\title{
On Cancer Cell Cycle and Universal Apoptosis Parameters Signaling Unravelled In Silico
}

\author{
Rosario M. Ardito Marretta* and Filippo Ales
}

Department of Structural, Aerospace Engineering and Geotechnics, University of Palermo, Viale delle Scienze 90128 Palermo, Italy

\begin{abstract}
Here, cell cycle in higher eukaryotes and their molecular networks signals both in $\mathrm{G}_{1} / \mathrm{S}$ and $\mathrm{G}_{2} / \mathrm{M}$ transitions are in silico replicated. Systems control theory is employed to design multi-nestled digital layers to simulate protein-toprotein activation and inhibition in the cancer cell cycle dynamics in presence of damaged genome. Sequencing and controlling the digital process of four micro-scale species networks (p53/Mdm2/DNA damage; p21mRNA/cyclin-CDK complex; CDK/CDC25/wee1/SKP2/APC/CKI and apoptosis target genes system) paved the way for unravelling the participants and their by-products having the task to execute (or not) cell death. The results of the proposed cell digital multi-layers give reason to believe in the existence of an universal apoptotic mechanism. We identified and selected cell checkpoints, sizers, timers and specific target genes dynamics both for influencing mitotic process and avoiding cancer proliferation as much as for leading the cancer cell(s) to collapse into a steady stable apoptosis phase.
\end{abstract}

Keywords: Cell signalling, cell digital simulator, cancer cells, apoptosis.

\section{INTRODUCTION}

Both in higher eukaryotes and yeast, the duty cycle period between two successive divisions depends on cell size which can be divided into two sub-phases, one called sizer and timer the other one [1-5].

New approaches as mathematical modeling, non linear system dynamics and digital signal analysis are even more employed for deeper insights into cellular biological process [6-17].

Mathematical bifurcation analysis meets with outstanding success for modeling biochemical reactors and regulators of eukaryotes cell cycle in terms of molecular antagonism, hysteresis, irreversible transition up to intrinsic pathway of programmed cell death [18-22].

As regards cell growth, Tyson and colleagues [15-17,2325] suggest elegantly saddle-node bifurcation for the $G_{1} / S$ transition checkpoint and saddle-node-loop bifurcation for the $\mathrm{G}_{2} / \mathrm{M}$ phase checkpoint, so as to resume cell activities into a bistable system. However, other important features, such as sizers and timers remain to be explained.

Diametrically opposite opinions lead other authors $[1,2,18]$ to mathematically model cell cycle using Hopf bifurcation analysis in which sizers and timers arise naturally as features of cell signaling network.

Here, cell growth protein-to-protein signaling networks and their co-factors and by-products, see Fig. (1), are firstly translated into mathematical frames and then linked to each other via multi-nestled digital layers, sub-blocks and control wirings, see Figs. (2-5).

*Address correspondence to this author at the Department of Structural, Aerospace Engineering and Geotechnics, University of Palermo, Viale delle Scienze 90128 Palermo, Italy; Tel: +3909123896747; Fax: +39091485439;

E-mail: romario@unipa.it
We take into account all features of the cell cycle digital activities, including natural or aberrant cell growth parameters, for identifying those species capable to govern and control not only the transition phases $\mathrm{G}_{1} / \mathrm{S} \div \mathrm{G}_{2} / \mathrm{M}$ but also the apoptosis mechanism as extreme defence against DNA damage proliferation.

In this paper, a "next generation" digital scheme is given for greatly enhancing a previous cell master simulator $[26,27]$. It in silico includes multi-layers design of four micro-scale species networks, see Figs. (1-5), concerning p53/Mdm2/DNA, p21mRNA/cyclin-CDK, CDK/CDC25/ wee1/SKP2/APC/CKI, and apoptosis target genes system, i.e., APAF1, DINP1, AIP1, cytoc and Apoptosome (assumed as digital parameter to check apoptosis phase triggering).

For the higher eukaryotes cell cycle under examination, once different input signals pathways of p21mRNA are injected and/or mutant species are considered, the "all-atonce" performed simulations of the 4-based sub-networks protein complex unravel species network signaling cofactors and by-products, up to now unknown, influencing not only the cell growth factors but, acting in synchrony within a complex digital mechanism, how they can become executioners (or not) of the cell fate.

We demonstrate that this mechanism, further discussed, is independent from cell cycle environmental input and its activation pathways line up with general principles which may thus be assumed to be universal.

\section{(BIOCHEMICAL) MATERIALS AND (BIOTECHNO- LOGICAL) METHODS}

As previously mentioned, a nestled digital multi-layer has been designed for in silico simulating cancer cell cycle through four interlinked micro-scale species networks: a) p53/Mdm2/DNA; b) p21mRNA/cyclin-CDK; c) CDK/ CDC25/wee1/SKP2/APC/CKI, and, d) apoptosis target 


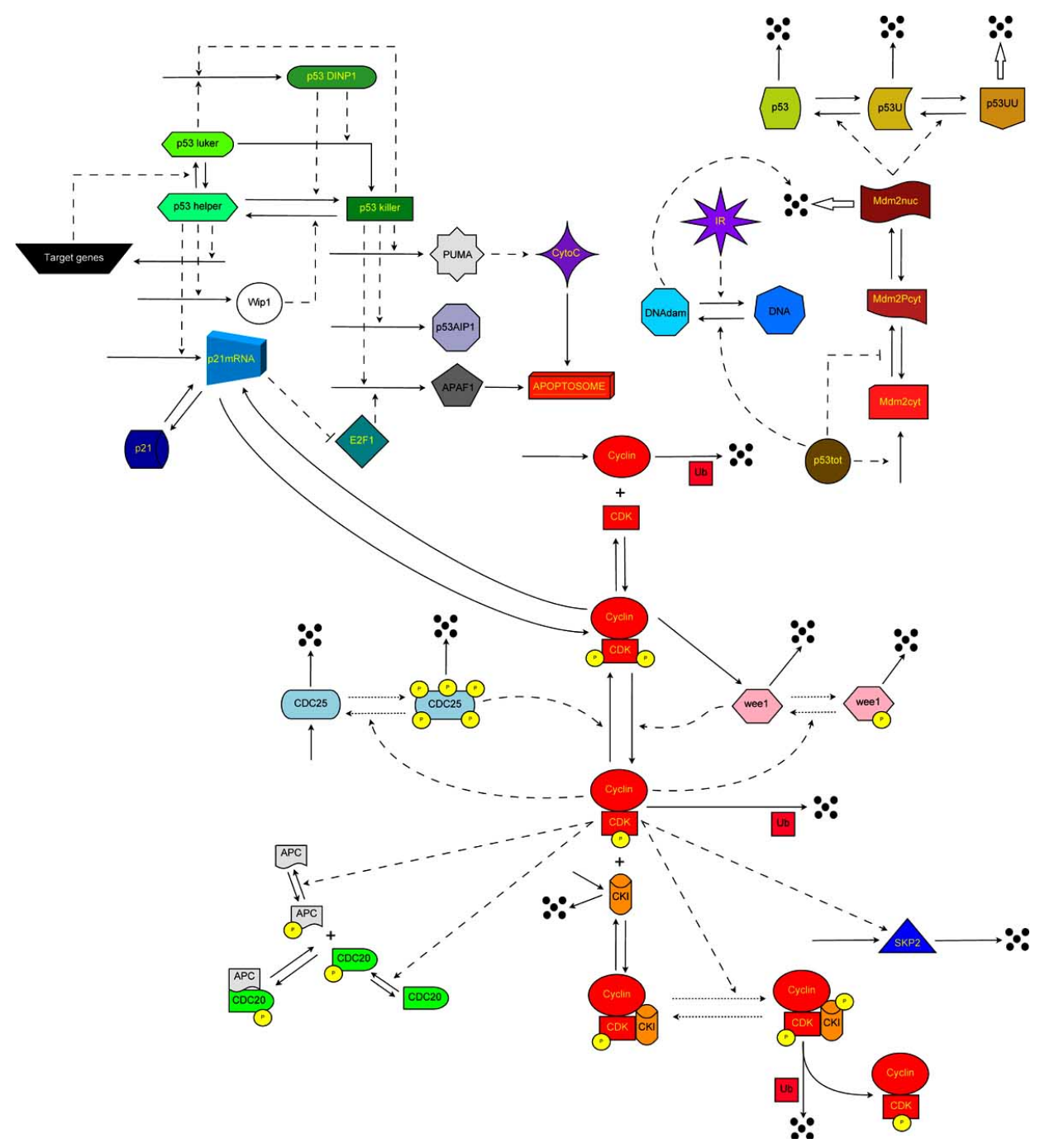

Fig. (1). Wiring diagram of the molecular model of cancer cell species dynamics.

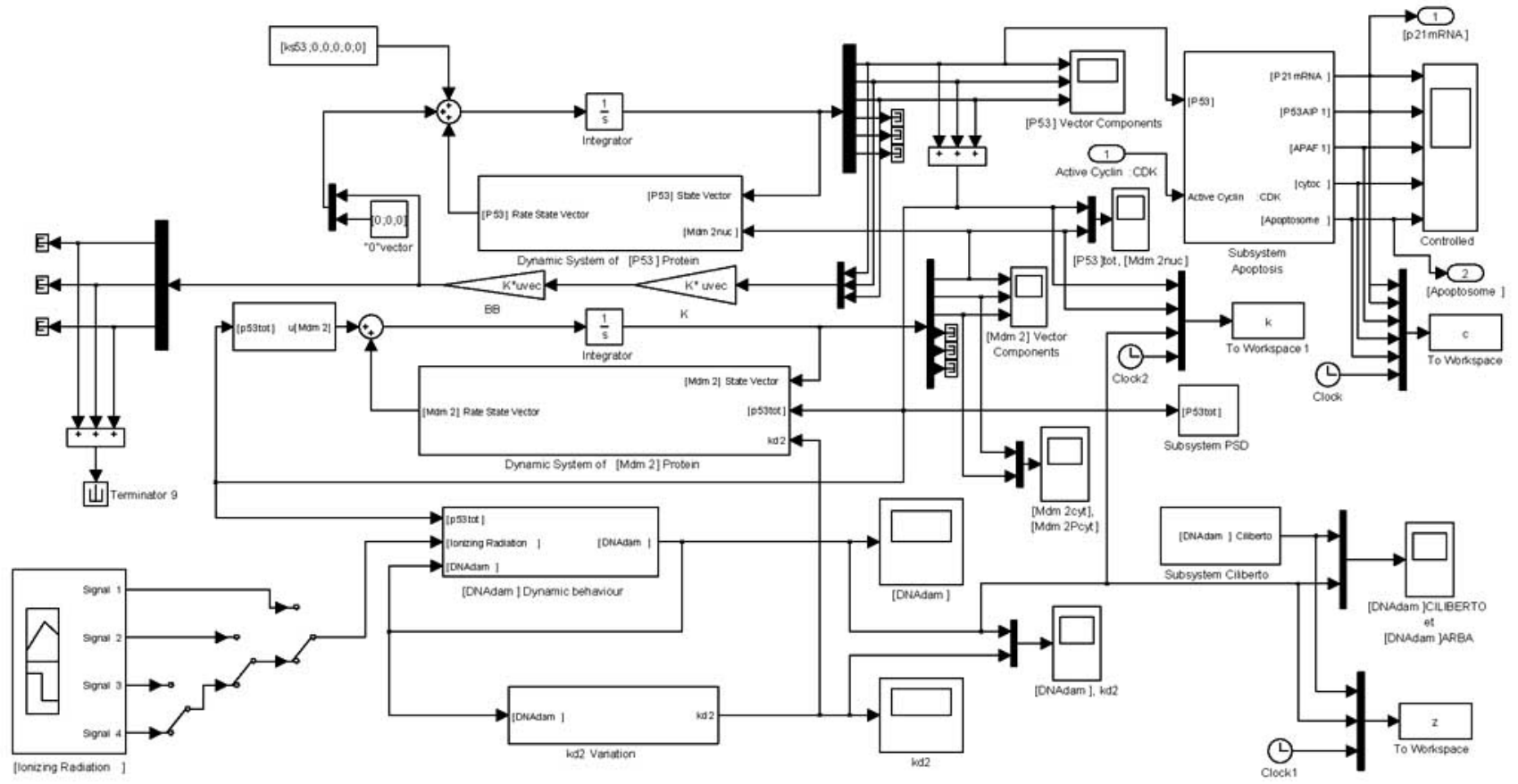

Fig. (2). Human cell DNA damage-repair master digital simulator (overall view). 


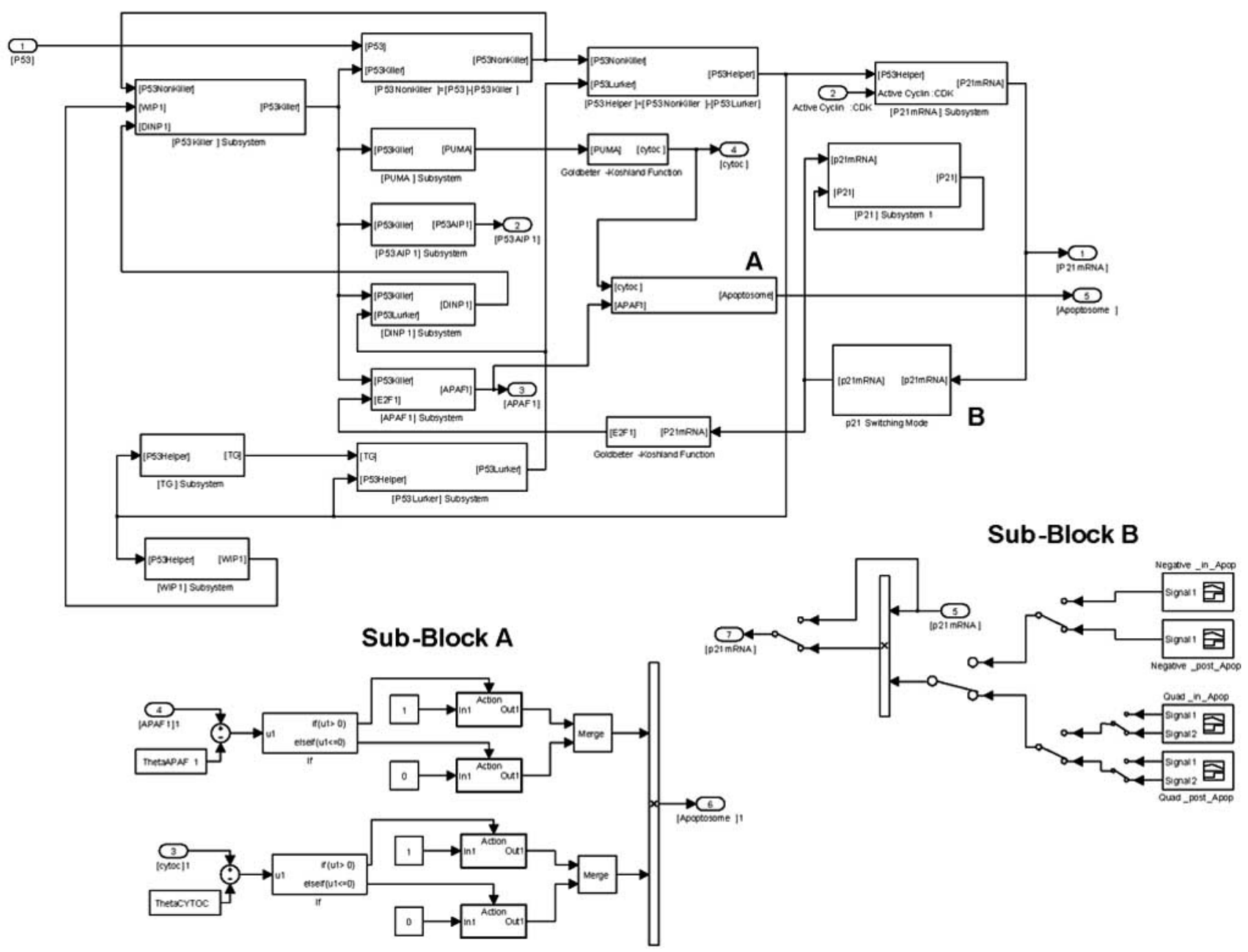

Fig. (3). Digital sub-networks of p21mRNA/p21 and apoptotic target genes.
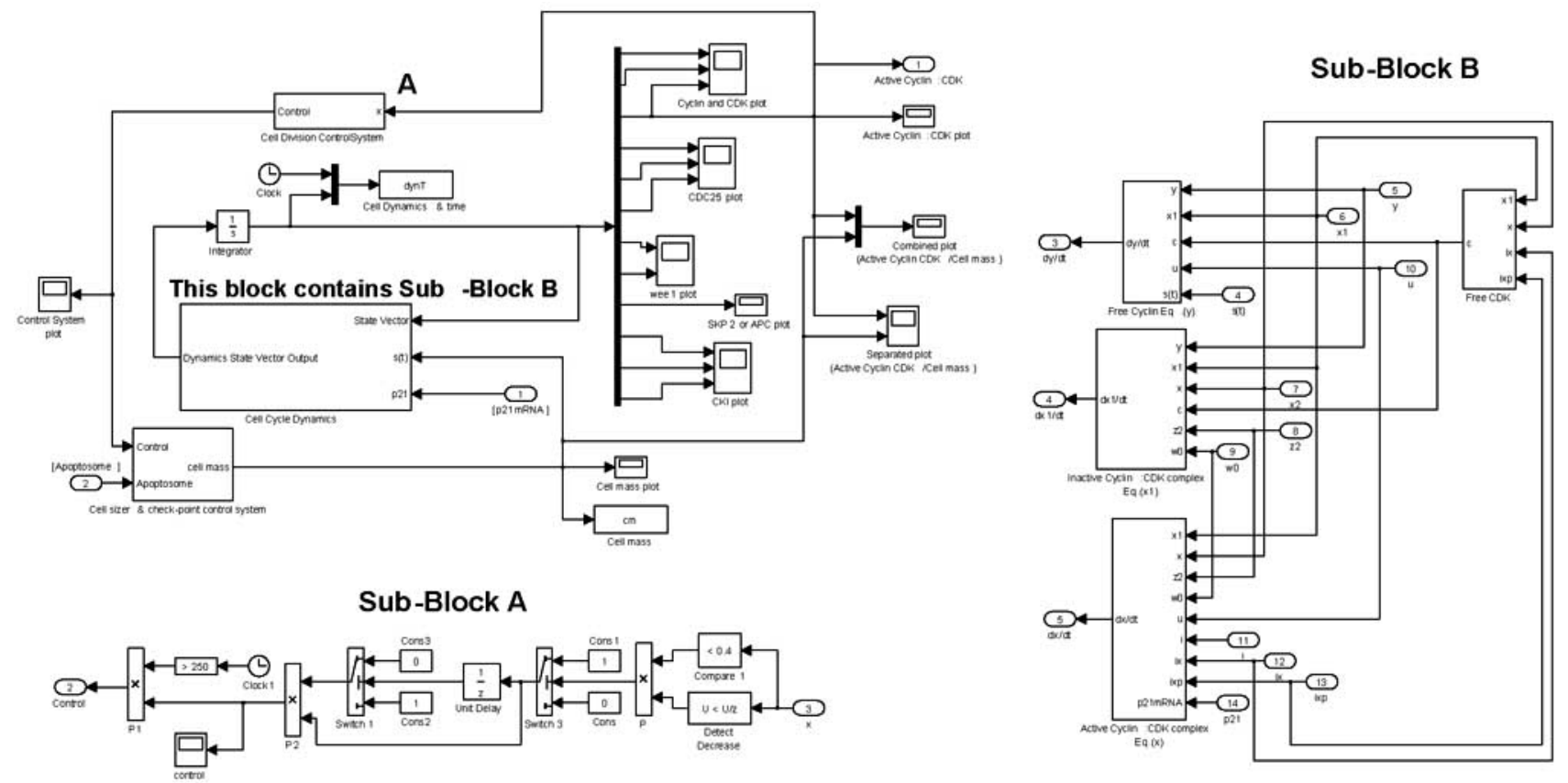

Fig. (4). Sub-layer of the cell sizers, timers and checkpoints network. 


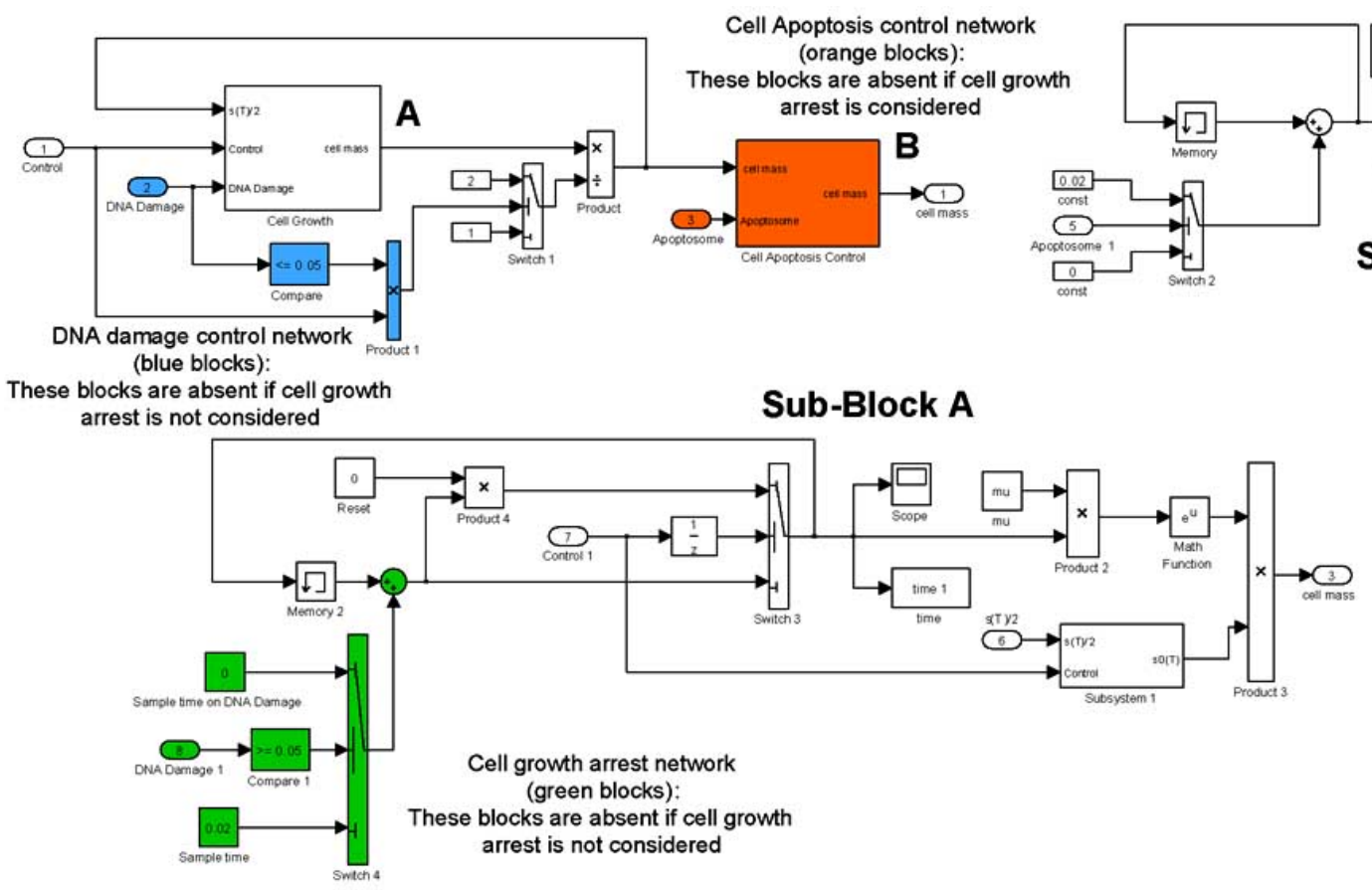

Fig. (5). Digital sub-network of cell cycle activities (division, cell fate, growth and growth arrest).

genes system, i.e., cyclin-dependent kinase CDK/CDC25/ inhibitor, p21; p53-regulated apoptosis-inducing protein 1, p53AIP1; apoptotic protease activating factor 1, APAF1; and target gene "cytoc" as a functional of APAF1 in apoptosome expression being its value, expressed by the Heaviside function, equal to 1 (or zero) for matching (or not) the cell death.

\section{Biochemical and Digital Sub-Layer of p53/Mdm2/DNA Network}

In cell cycle of cancer pathologies, the oncosuppressor p53 protein induces the transcription of genes in charge of the cell-cycle arrest, DNA repair and apoptosis [28-40].

In a human cell, the biological response of ATM, p53 and Mdm2 species is interlinked with, and quite similar to, the output response of oscillating network dynamics. If DNA damage exceeds a threshold, the p53 pulses to activate transcription of the p21 gene and other species for apoptosis execution [41-56].

In the p53/Mdm2/DNA network digital design, both positive and negative feedbacks are considered in pulsing response to DNA damage reproducing (and fitting quite well) experimental data in quantitative details $[26,27,30]$.

We start by taking into account the protein forms of p53 (p53 mono-ubiquitinated, p53 poly-ubiquitinated and p53 total, i.e., p53 $3_{\mathrm{U}}, \mathrm{p} 53_{\mathrm{UU}}$ and $\mathrm{p} 53_{\mathrm{tot}}$, respectively) and $\mathrm{Mdm} 2$ (nuclear, cytoplasmic and phosphorylated, i.e., Mdm2 $2_{\text {nuc }}$, $\mathrm{Mdm} 2_{\text {cyt }}$ and $\mathrm{Mdm} 2_{\text {Pcyt }}$, respectively) with their timedependency from a set of equations. From a biotechnological point of view, the problem consists of processing a set of equations in a computational space, i.e., the state space which mathematically represents all the possible conditions and combinations of the variables of the problem. Here, the biological basis upon which the present p53/Mdm2/DNA damage digital model are those of Ciliberto et al. [30]. In the present simulations, a generic variable (DNA damage) DNA $_{\text {dam }}$, depends upon $I R$ (Ionizing Radiation). The mathematical translations and the corresponding digital subblock features are obtained as displayed in Fig. (2). Both p53/Mdm2 positive/negative feedback loops are generated and processed via the control matrices $\mathbf{B B}$ and $\mathbf{K}$ which are located between the Mdm2 and p53 proteins dynamic systems for a real-time check of the digital output variables (protein kinases and their time rates).

BB is a matrix block that is employed to build up the control matrix feedback, $\mathbf{K}$, in the LQR (Linear Quadratic Regulator) system; $\mathrm{k}_{\mathrm{d} 2}$ block digitally performs the rate constant for degradation of $\mathrm{Mdm} 2_{\text {nuc }}$.

Biotechnological processors are applied to the continuous time-linear p53/Mdm2/DNA damage system that can be summarized by:

$\dot{\mathbf{x}}=\mathbf{A} \mathbf{x}+\mathbf{B} u$

where:

$\dot{\mathbf{x}}$ is the derivative of state-vector,

$\dot{\mathbf{x}}(t)=\mathbf{P}\left(\left[M d m 2_{n u c}(t)\right]\right) \mathbf{x}(t)+b$

is the matrix for $\mathrm{p} 53$ transcription factor dynamics, $\mathbf{B}$ is the matrix for the transition (LQR) input-state, $u$ is the LQR input.

The feedback control law requires that:

$u=-K x ; K=R^{-1} B^{T} P$

$A^{T} P+P A-P B R^{-1} B^{T} P+Q=0$

$\mathbf{Q}$ is a semi-definite positive matrix containing, as elements, the inverse of the square maximum values of the proteins concentrations $\mathbf{R}$ is a definite positive matrix containing, as elements, the inverse of the square maximum 
values of the input signals $\mathbf{K}$ is the control matrix feedback $\mathbf{P}$ is the stabilizing solution of Riccati equation (in matrix terms). The state-vector for p53 and its concentrations shall be

$$
\underline{x}(t) \triangleq\left[[p 53]\left[p 53_{U}\right]\left[p 53_{U U}\right][p 53]\left[p 53_{U}\right]\left[p 53_{U U}\right]\right]^{T}
$$

Once the proposed state-space representation gives the same results as the model of Ciliberto et al. [30], the digital optimal control law has been implemented and based on the assumption that the matrix is such that $\mathrm{Mdm} 2_{\text {nuc }}$ is equal to a constant

In a similar way:

$$
\dot{\mathbf{z}}(t)=\dot{\mathbf{M}}\left(\left[p 53_{t o t}(t)\right], k_{d 2}(t)\right)+\mathbf{c}\left(\left[p 53_{t o t}(t)\right]\right)
$$

Moreover, some auxiliary matrices have been employed as follows for the LQR shakedown

$$
\mathbf{K}=L Q R(\mathbf{P}, \mathbf{B B}, \mathbf{Q}, \mathbf{R})
$$

where

$$
P=\left\{P_{i j} ; i, j=1,2,3 ; P_{i j} \in \Re\right\}
$$

The optimal control matrix has to accomplish the task to accelerate the DNA repair process according to the equation:

$$
\frac{d\left[D N A_{d a m}\right]}{d t}=k_{D N A}[I R]-k_{d D N A}\left[p 53_{t o t}\right] \frac{\left[D N A_{d a m}\right]}{J_{D N A}+\left[D N A_{d a m}\right]}
$$

\section{Biochemical Assumptions and Digital Sub-Layer of p21mRNA/cyclin-CDK Complex}

We assume p21mRNA is indirectly connected to DNA damage capable of activating chk1 protein which inhibits CDC25 activity. In agreement with but differently from Qu et al. $[1,2]$, we translate biochemical p21 mRNA/cyclin-CDK chain kinase reactions into a differential equation

$$
\frac{d x}{d t} \propto f(z) x_{1}-g(w) x-\delta p 21 m R N A x
$$

For digitally designing and checking the cell multilayers, we assume a numerical value for $\delta$ so as to obtain the same starting level of DNA damage of Qu et al. [1]. The digital scheme of p21mRNA/cyclin-CDK complex involves a multi-nestled layer. The first (see "[p21] Subsystem1" block circuitry and Sub-Block A in Fig. (3)) replicates in silico the protein-to-protein signaling between p21 and all the considered forms of p53 via Goldbeter-Koshland function. A complex digital switching chain (see Sub-Block B of Fig. (3)) injects several combinations of p21mRNA input signal during cell cycle transition phases. Both natural and controlled p $21 \mathrm{mRNA}$ signalling pathways are generated and further processed by the cell growth dynamics digital multi-layers of Fig. (4).

\section{Biochemical Assumptions and Digital Sub-Layer of CDK/CDC25/wee1/SKP2/APC/CKI Network}

Following Qu et al. [1] and the proteins kinase map of Fig. (1), the biochemical synthesis of the considered species has to be translated into differential equations.
Inactive cyclin-CDK is obtained by phosphorylating CDK at Thr14 and Tyr15 which are, at the same time, dephosphorylated by CDC25. Wee1 acts for restoring phosphorylation process. Digitally speaking, CDC25 must be phosphorylated by active cyclin-CDK complex for becoming active and giving a positive feedback loop.

Conversely, wee1 becomes inactive via its phosphorylation which is catalyzed by active cyclin-CDK complex so giving a double-negative feedback loop. In sequence, active cyclin-CDK is inhibited via its inhibitor, CKI.

In the protein map of Fig. (1), all the CDC25 forms are degraded via their concentrations-dependent constant $[55,56]$.

Speculatively speaking, both $\mathrm{G}_{1} / \mathrm{S}$ transition and $\mathrm{S}$ phase are interested by expression and phosphorylation of SKP2 which is only linked to CDK2 $[43,45,56]$. Proportionally to its concentration, degradation of CKI occurs with synthesis constant rate.

The digital sub-layers of Figs. (4-5) represent the central processing unit of the overall cell digital master simulator. This unit performs the biotechnological task of processing the obtained digital signals of the cell cycle (dynamical) division species (APC, SKP2, cyclin-CDK, CDC25, wee1, $\mathrm{CKI}$ ) in positive/negative feedback loops and gives orders to Sub-Blocks A and B (see Fig. (4)) of sequencing and controlling cell checkpoints, timers and sizers for all the input variables of the considered four micro-scale species networks previously mentioned. Cell cycle transitions are processed by sub-layers of Sub-Blocks (see Fig. (5)) and interlinked to cell growth and division dynamics, growth arrest and cell fate. According to digital architecture and control theory, DNA damage network, cell apoptosis and cell growth arrest wirings networks (see blue, orange and green blocks of Fig. (5)) can be disconnected if cell growth arrest is not considered (see more functional details in the captions of Figs. (4-5)).

\section{Biochemical Assumptions and Digital Sub-Layer of Apoptosis Network}

As regards the molecular kinetics for apoptosis network, we consider that $\mathrm{p} 53_{\text {killer }}$ activates PUMA, p53DINP1 and p53AIP1 genes. On the other hand, PUMA induces release cytoc for activating - in cascade - APAF1 and caspase9. The APAF1 binds both p53 and E2F1. It is assumed that the p53 phosphorylation on Ser46 depends on the amount of p53DINP1 and Wip1; if p53DINP1 is overexpressed (when compared to Wip1), Ser46-dependent phosphorylation of $\mathrm{p} 53$ gives the $\mathrm{p} 53_{\text {killer }}$ form. The roles of $\mathrm{p} 53_{\text {helper }}$ are resumed as follows: $\mathrm{p} 53_{\text {helper }}$ preferably induces p $21 \mathrm{mRNA}$ which in turn induces cell cycle arrest and gives time for DNA damage repair; arresting CDK activity, p21mRNA indirectly produces the retino-blastoma protein binding and inhibiting E2F1, thereby arresting APAF1 production; p53 helper $_{\text {blocks }}$ backwards $\mathrm{p} 53_{\text {killer }}$ by activating Wip1 which inhibits Ser46 phosphorylation. The last form of p53, i.e, p53 lurker can be turned into p53 $3_{\text {killer }}$ by p53DINP1. p53, p53 $3_{\mathrm{U}}$ and $\mathrm{p} 53_{\mathrm{UU}}$ refer respectively to 0,1 and 2 moieties attached and their sum represents the total $\mathrm{p} 53$.

Apoptotic species scheme is built up by multi-nestled layers: by-wire connections interlinks "Subsystem 
Apoptosis" (see Fig. (2)) to p53 forms and cyclin-CDK subblocks; also, the p21mRNA digital block (see Fig. (3)) and the sub-layers of "Cell Division Control System", "Cell Cycle Dynamics" and Cell sizers \& checkpoint control system" (see Figs. (4-5)) trigger concurrent and dialoguing signaling with apoptosis target genes network.

\section{RESULTS}

\section{Cell Cycle Arrest on DNA Damage Target Genes Response}

Separately, two square-wave radiation signals were emitted for causing a fixed level of DNA damage and evaluating (if any) sizers, timers and checkpoints variations.

The onset of these two distinct signals is tuned and exerted for $10 \mathrm{~min}$ both in the $\mathrm{G}_{1} / \mathrm{S}$ phase (at $\mathrm{t}=50 \mathrm{~min}$ ) and in $\left.\mathrm{G}_{2} / \mathrm{M}\right\}$ transition phase (at $\mathrm{t}=1100 \mathrm{~min}$ ), respectively. Pictorial outfits of apoptotic target genes responses to DNA damage impulse at $\mathrm{t}=50 \mathrm{~min}$ (see Fig. (6)) reveal doublepulsing features of $\mathrm{p} 21 \mathrm{mRNA}$ along the timespan. After a quiescent state, within $200 \div 250 \mathrm{~min}$, p21mRNA starts to rise its level of synthesis according to a first instability in p53AIP1, APAF1 and cytoc pathways; looping in chain, for this time window, p21mRNA underexpression runs in choral way with a low speed degradation rate of APAF1.

Once a second instability of the apoptotic species occurs, $250 \div 300$ min, p $21 \mathrm{mRNA}$ radically changes its pathway and increases with high speed synthesis rate. Along $250<\mathrm{t}<2000 \mathrm{~min}$, p21mRNA oscillation pulses with a constant amplitude and lowest frequency. For the time window $2000<\mathrm{t}<5000 \mathrm{~min}$ (digitally, $t \rightarrow \infty$ ), p21mRNA expression assumes stable and undamped oscillations and begins to pulse in-phase with active cyclin-CDK frequency (see also Fig. (7)). Conversely, the APAF1 degradation (inverse) gradient increases and its concentration falls during the timespan $200 \div 300 \mathrm{~min}$; past this time window, it remains quiescent.

The digital simulations make almost superimposable the mutual dynamics of these two species, active cyclin-CDK and $\mathrm{p} 21 \mathrm{mRNA}$, regulated with a negative feedback loop with those obtained by bifurcation analysis and confirm the p $21 \mathrm{mRNA}$ low speed synthesis rate. Instead, cell species signaling networks involve high speed rate of p21mRNA synthesis as a response to damaged genome. Comparison among cell growth regulation species (see Fig. (7)) with undamaged cell cycle [1], show delay in active cyclin-CDK (as well as APC) synthesis causing a variation in the "natural" cell cycle timespan. This cell cycle time window delay being equal to the cell growth time window arrest. Looking at the cell mass and active weel dynamics panels (Fig. (7)), after a transient regarding the first two instabilities of p53AIP1, APAF1, cytoc and the first two oscillations of p $21 \mathrm{mRNA}$, one has to note that these cell parameters pulse in-phase with APC and active cyclin-CDK complex. Thus, only the cellular timer phase is affected by DNA damage repair while checkpoints and sizers remain steady stable. This causes a constant pulsing frequency phase variation among the cell cycle-dependent species of aberrant cell and those concerning a cell structure in which DNA was repaired. In the second simulation (see Fig. (8)), DNA damage triggers at $\mathrm{t}=1100 \mathrm{~min}$ and cell network species show absence of a bistable behavior of active cyclin-CDK in mitotic phase; this implies no modifications in p21mRNA response to DNA damage repair. Within the timespan $1150 \div 1950 \mathrm{~min}$, cell starts division into two daughter cells and the increasing cyclin-CDK complex activity acts for inhibiting p21mRNA overexpression in the mother cell. APC, cell mass and wee1 panels (see Fig. (9)) pictorially display the capability of cell digital multi-layer platform to describe cell(s) checkpoints, timers and sizers. Differently from the previous simulation (DNA damage at $\mathrm{t}=50 \mathrm{~min}$ ), here cell cycle steps forward the time window $1150 \div 1950 \mathrm{~min}$ in which $\mathrm{G}_{2} / \mathrm{M}$ transition occurs and differences between the two performed simulations become more evident. Strictly speaking, at $\mathrm{G}_{2} / \mathrm{M}$, high speed rate activities of cyclin-CDK complex are combined with p21mRNA modified pulsing pathway (lowest peak and highest frequency); when mitotic process ( $M$ phase) is accomplished, p21mRNA decreases its frequency (and
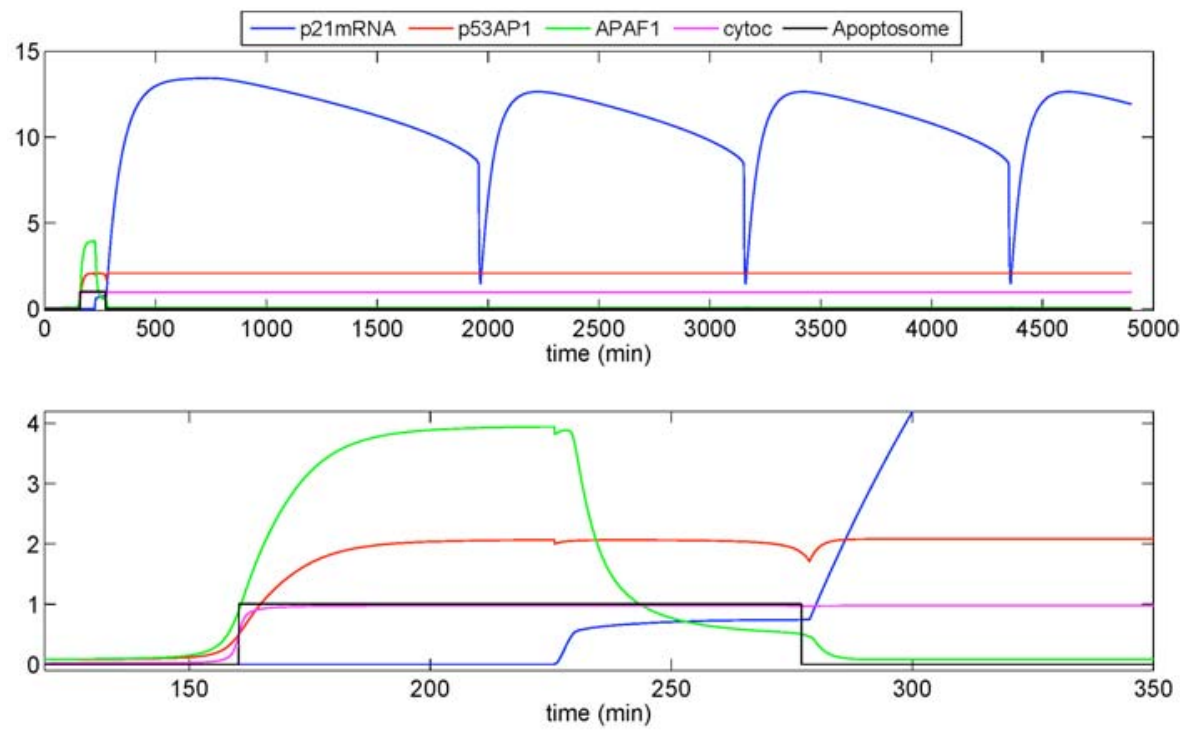

Fig. (6). Output response of apoptotic species network as a consequence of DNA damage at $\mathrm{t}=50 \mathrm{~min}$. 

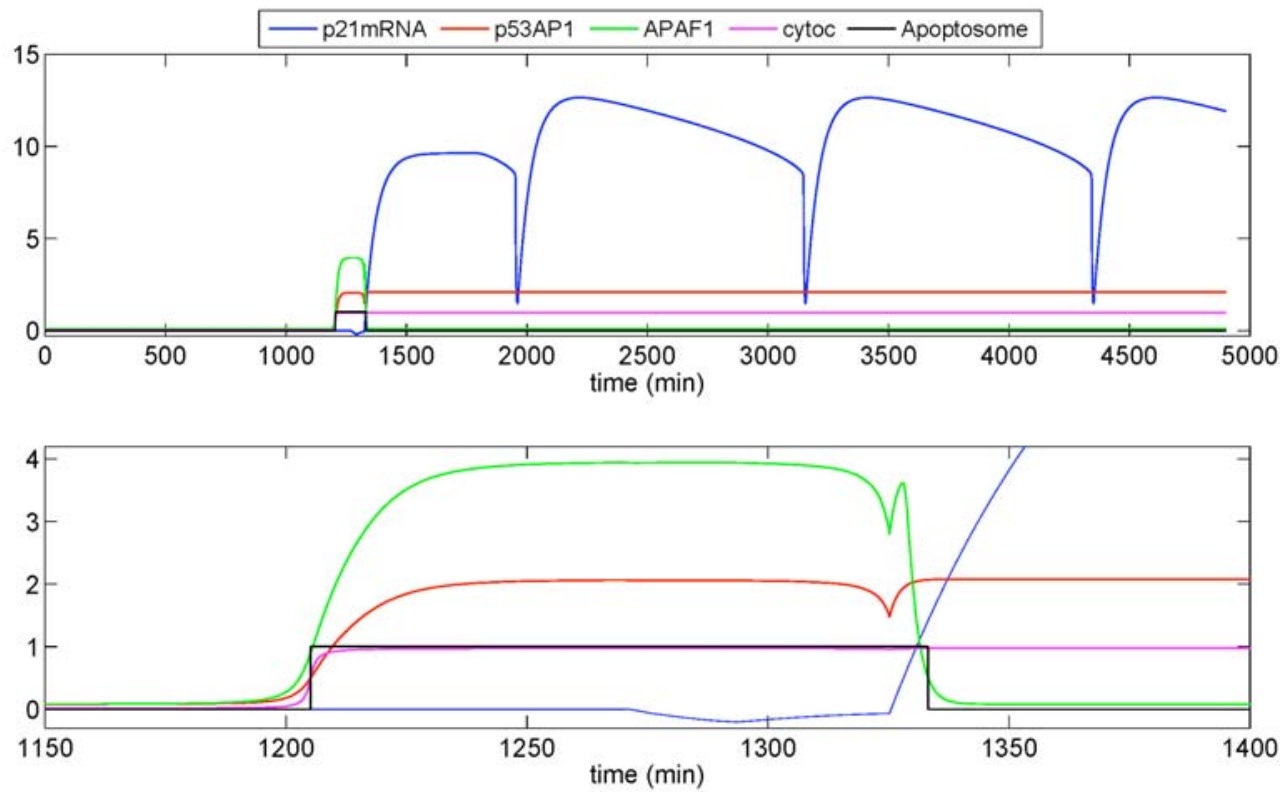

Fig. (7). Output response of apoptotic species network as a consequence of DNA damage at $t=1100 \mathrm{~min}$.
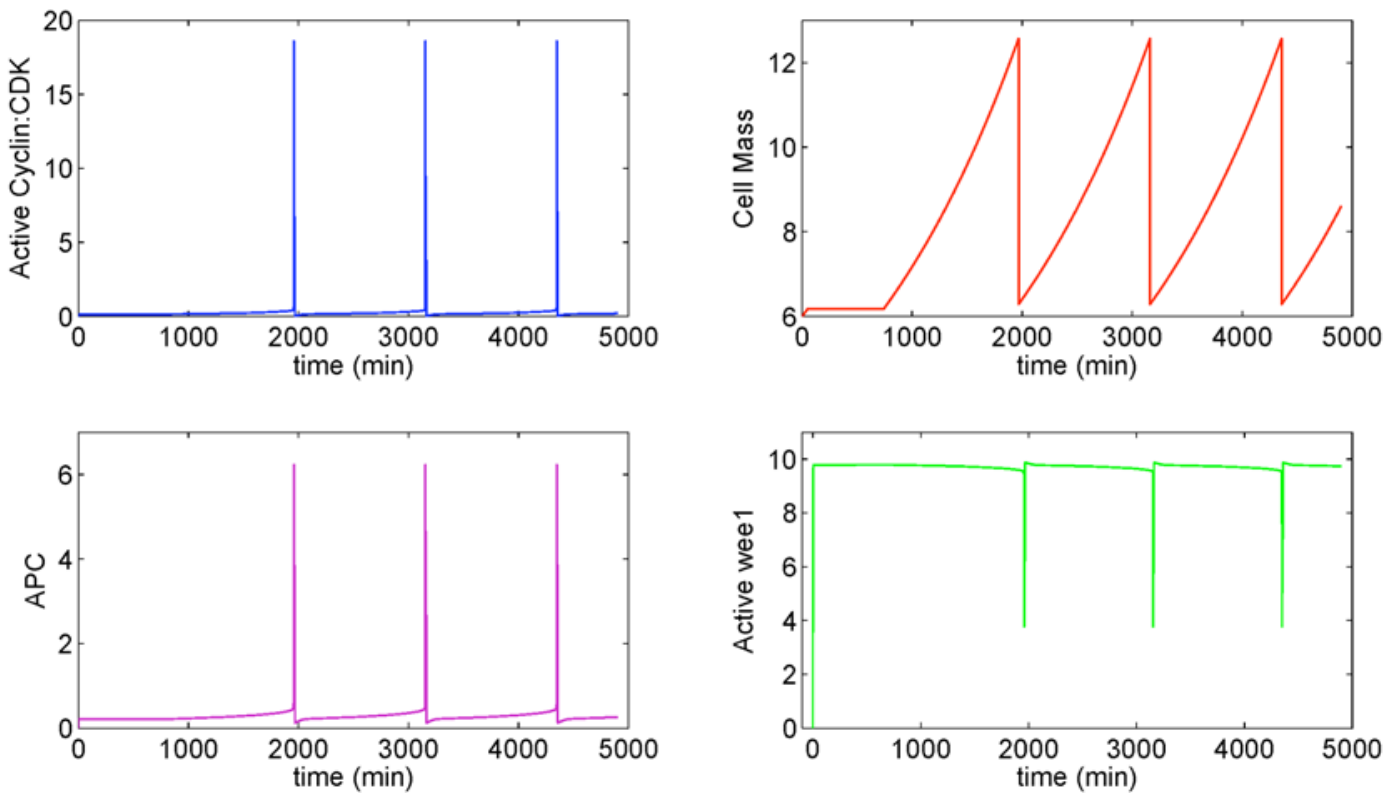

Fig. (8). $G_{1} / S \div G_{2} / M$ transition species and cell mass evolution for growth halted at $t=50 \mathrm{~min}$.

highest peak of concentration) in the daughter cells and reenters a steady state undamped oscillations in-phase with active cyclin-CDK complex, APC and wee1.

As a consequence, the cell growth time arrest is equal to the delay of cell cycle species synthesis and cell checkpoints, timers and sizers behaviors are the same of those evaluated at $\mathrm{t}=50 \mathrm{~min}$.

\section{p21mRNA "Tracking" Signaling and Apoptosis Network}

Normally, if a DNA damage affects genome integrity during physiological cell cycle, molecular emergence resources system is immediately activated Digitally (and biochemically), this cell defence machinery backwardly and forwardly pulses a signaling "dialogue" towards critical cell cycle reactors and factors conditioning repetitive cycles, checkpoints and size progression. Essentially, the p53/Mdm2 feedback loop system digital behavior consists of zero, one, two or more pulses as a function of DNA damage. Based on previous studies [26,27,30], a key role is played by p21mRNA and its dynamics. If irreversible DNA damage is present, p $21 \mathrm{mRNA}$ synthesis remains almost quiescent at the beginning of the apoptotic time window but triggers suddenly with a concurrent and specific pathways of apoptotic target genes having as a consequence the closure of the apoptotic time window and allowing the cell to avoid its fate.

This peculiar and malicious mechanism of p21mRNA was previously studied by the first author [27] for identifying its interaction with apoptosis genes. In that previous digital 

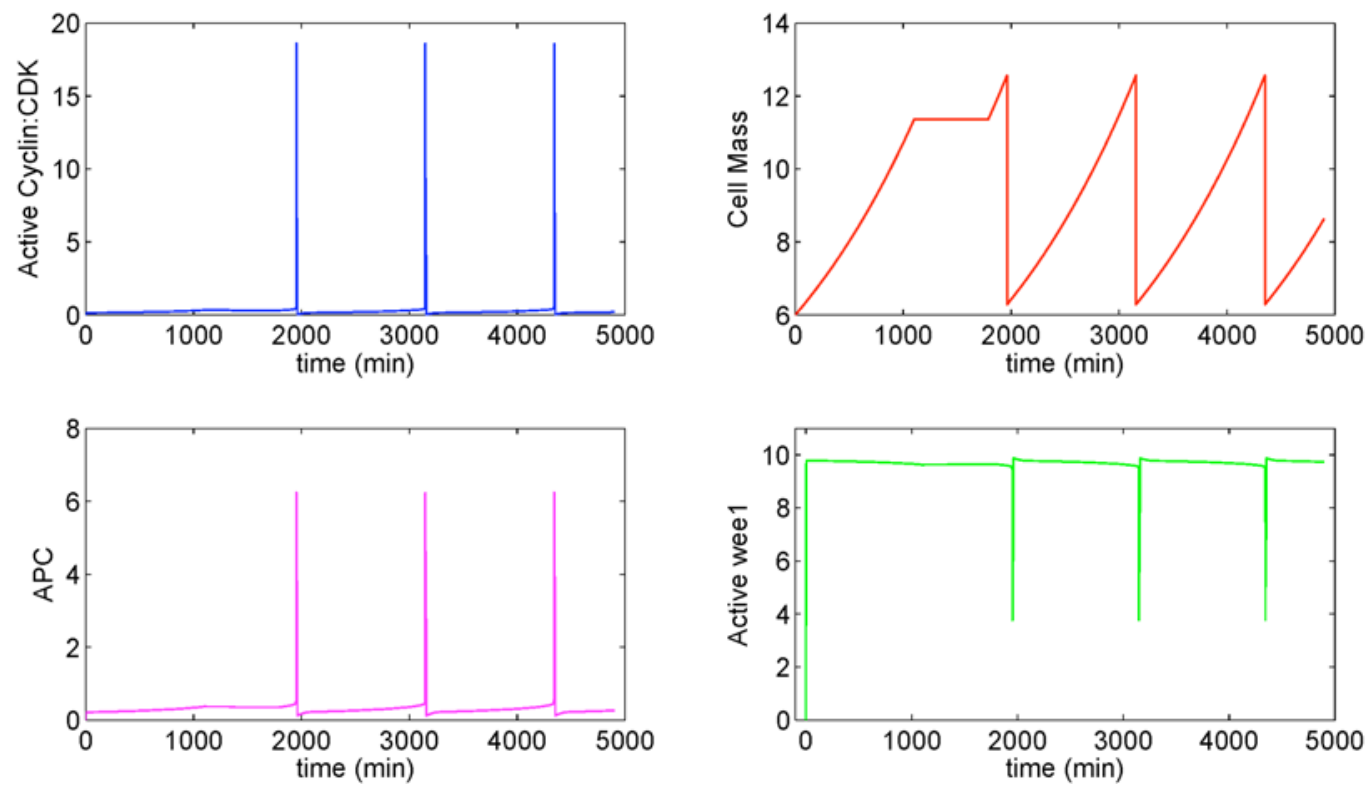

Fig. (9). $G_{1} / S \div G_{2} / M$ transition species and cell mass evolution for growth halted at $t=1100 \mathrm{~min}$.

approach, the results are in experimental agreement with those of Viale et al. [55]. In that case, p53-independent p21mRNA overexpression showed an unforeseen dynamics when related to the apoptosis genes pathways. When different signals of $\mathrm{p} 21 \mathrm{mRNA}$ were triggered, the response of the p53/Mdm2 network radically changed into an impulse train of prolonged undamped oscillations whose amplitude and frequency is one order higher than the case in which the DNA was quickly repaired. Looking (clockwise) at the panels of Fig. (10), we evaluate the apoptosis p21mRNA signal-dependency and demonstrate a sort of "digitalsequenced tracking radome" property of p21mRNA to instantly identify the wavelengths and frequencies of the apoptotic species and intercept their gradient inversions. For this aim, we suppose different signal pathways of p21mRNA over different triggering timespans.

At first, let p21mRNA be represented by a negative linear-ramp signal in an aberrant cancer cell.

We carry on simulations for two timespans, 114.4$144.85 \mathrm{~min}$, in phase with the apoptotic time window, and $200 \div 1200 \mathrm{~min}$, respectively. For the first timespan, the results sketched in Fig. (10) show p21 upregulation almost vanishing and the remaining apoptotic species release their brakes and freely pulse toward a choral tuning at the same inflexion point at the same time location. The following apoptosis phase has no need of a second pulse and it remains permanently active.

The "tracking" properties of p21mRNA are confirmed even though it is again conceived as a negative linear-ramp signal all over a time-span of $200 \div 1200 \mathrm{~min}$ (i.e., past the natural apoptotic phase in the presence of irreparable DNA damage). In fact, p $21 \mathrm{mRNA}$ overexpression immediately occurs to intersect the inflexion point of APAF1 time rate.

This successfully occurs but two parameters come into play and change p21mRNA pathway: inversion of the p21mRNA upregulation time rate and the second pulse of APAF1. p21mRNA, like a digital CPU, exploiting to the utmost its direct "tracking memory" access, tries to follow this second pulse of APAF1 at its inflexion point for intersection. This is allowed for the second time but the third chance is denied because APAF1 reaches a steady-stable condition. According to this pulsating species dynamics, the apoptosis phase again shows two pulses and remains unchanged but with a frequency slightly lower $\left(1.7 \times 10^{-5}\right)$ than the natural frequency of the (unstable) apoptotic phase of a cancer cell with irreparable DNA damage.

The results sketched in the last two panels of Fig. (10) confirm the above assertions. Now, the simulations are performed using a different $\mathrm{p} 21 \mathrm{mRNA}$ pathway (mono-cycle square-wave signal) over the same timespans (114.4\% $144.85 \mathrm{~min}$ (apoptotic timewindow) and 200 $\div 1200 \mathrm{~min}$, respectively). The only difference is the p21mRNA upregulation tries to intersect the APAF1 inflexion point during its first pulse (having extremely high frequency equal to $3.61 \times 10^{-4}$ ) but the available remaining time window is too short for a second attempt. The apoptosis phases for both the considered timespans remain active with unchanged double-cycle pathways and natural frequencies. The simulation output for $200 \div 1200$ min (after apoptotic natural time window) is qualitatively the same of those relative to $114.4 \div 144.85 \mathrm{~min}$.

We now improved the cell master digital simulator by interlinking p21mRNA/cyclin-CDK and CDK/CDC25/wee1/ SKP2/APC/CKI networks to the apoptotic mechanism. In other words, the goal of the present paper is to find and give the way for selecting cell checkpoints, sizers, timers and specific target genes dynamics both for influencing mitotic process and avoiding cancer proliferation as much as for leading the cancer cell(s) to re-enter a steady stable apoptosis phase (see details in the next section).

\section{Unarrested Cell Cycle Depending on DNA Damage Target Genes Response for Wee1 Mutated Specie}

Without loss of generality, we considered the wee1 synthesis rate reduced one order giving the mutant form, wee1(-10). To evaluate the mutant cell response to genomic 

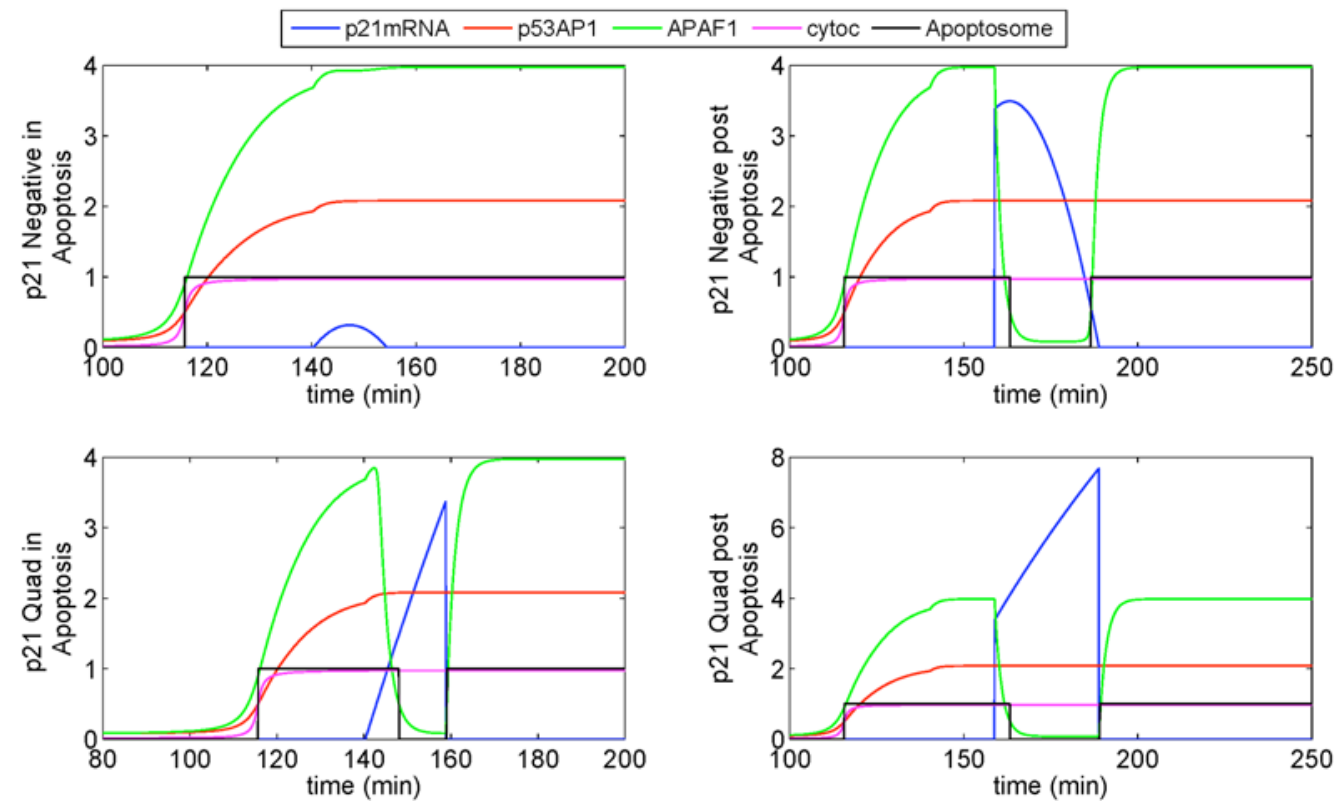

Fig. (10). Stand-alone apoptotic response control system (clockwise): above-left) output response of apoptotic target gene network having as input a p21mRNA negative linear-ramp signal in phase with apoptotic natural timespan of $114.4 \div 144.85$ min; above-right) output response of apoptotic target gene network having as input a p21mRNA negative linear-ramp signal applied at the end of apoptotic natural timespan of $114.4 \div 144.85 \mathrm{~min}$; below-right) output response of apoptotic target genes network having as input a p21 mRNA impulse square-wave signal in phase with apoptotic time window; below-left) output response of apoptotic target genes network having as input a p21mRNA impulse square-wave signal at the end of the apoptotic natural time-span.
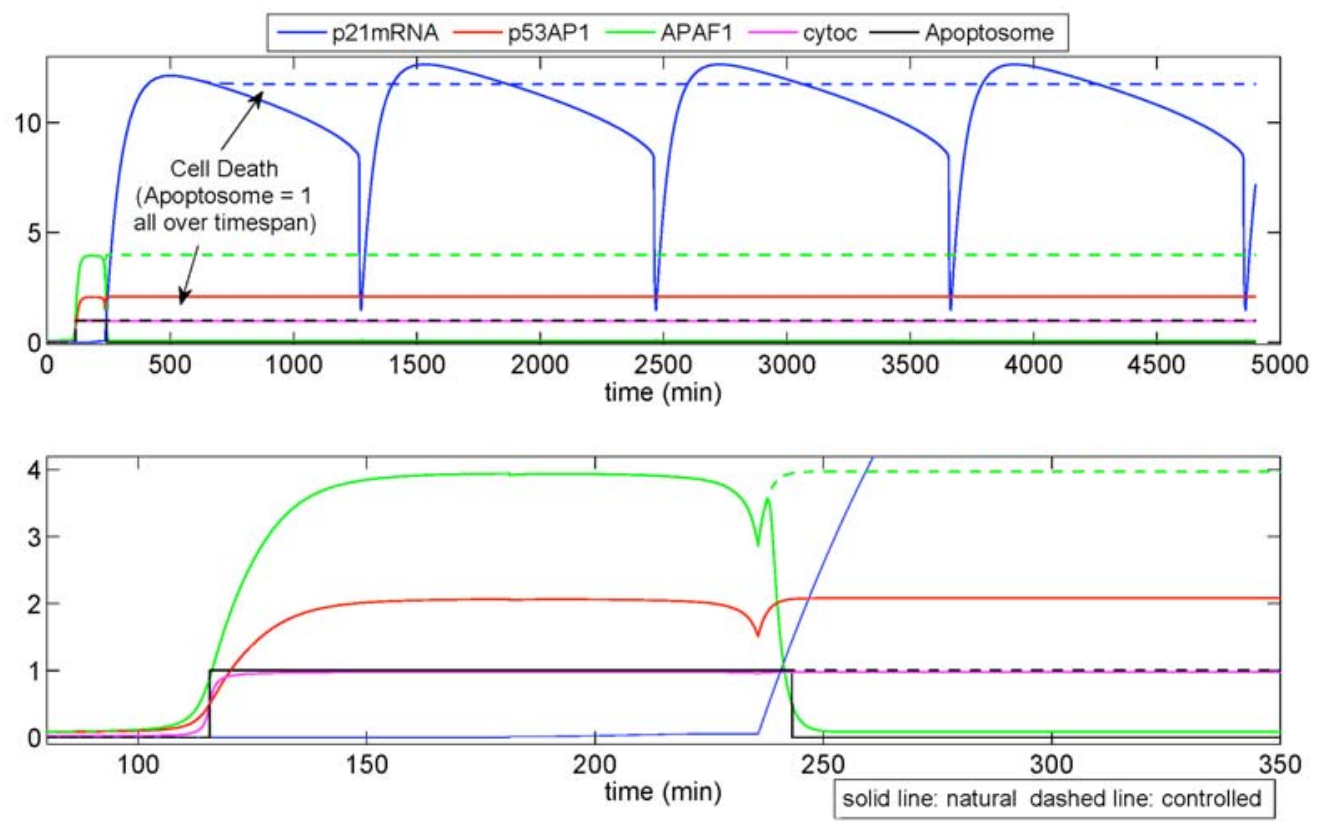

Fig. (11). Output response of apoptotic species network as a consequence of a DNA damage at $\mathrm{t}=0 \mathrm{~min}$.

damage, we again ignored cell cycle arrest during damage repair for the same two square-wave radiation signals previously employed. For ionizing irradiation at $\mathrm{t}=0 \mathrm{~min}$, wee1(-10) does not affect the apoptotic target gene response for both controlled and uncontrolled cell digital biochemical mechanisms; pictorial depications of APAF1, p53AIP1, cytoc and Apoptosome (see Fig. (15)) are the same as those obtained for the simulations described in the previous section (see Figs. (11-14)). To evaluate the global effects on cell cycle, we compare p $21 \mathrm{mRNA}$ pulsing frequency as obtained by Qu et al. [1], over the timespan $0<\mathrm{t}<2268.35 \mathrm{~min}$, to its proper oscillations. Mutated wee1 promotes initial unstable behavior of the cell division control species (two close concentration peaks of active cyclin-CDK and APC) and immediate cell division at $\mathrm{t}=75.04 \mathrm{~min}$ triggers (see Fig. (16)); as a consequence, at the end of its cycle, the bud mass is half a "normal" cell size. Thus, we can digitally assign a key role to mutant weel for inducing cell sizer and checkpoint mutations. 

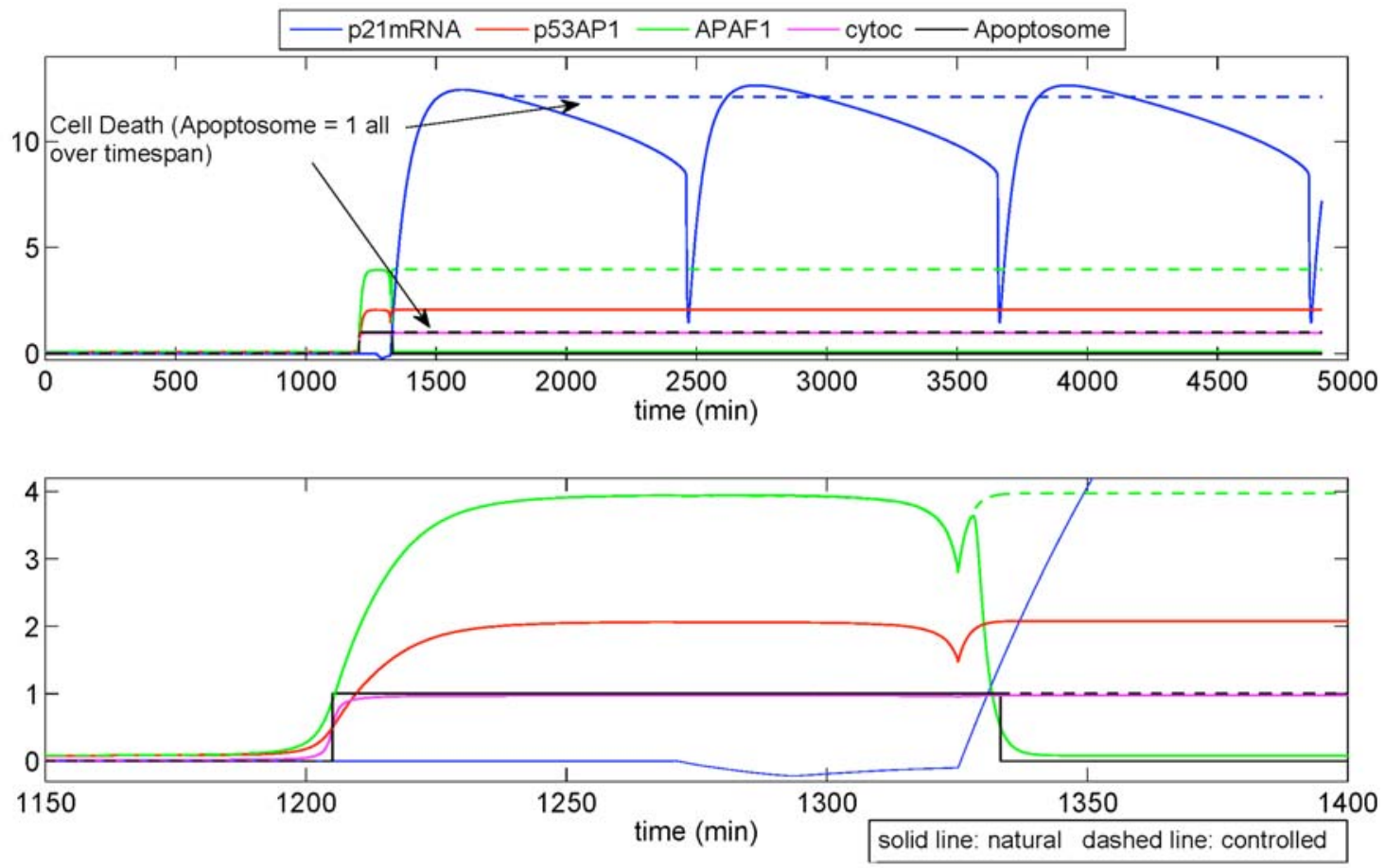

Fig. (12). Output response of apoptotic species network as a consequence of DNA damage at $t=1100 \mathrm{~min}$.
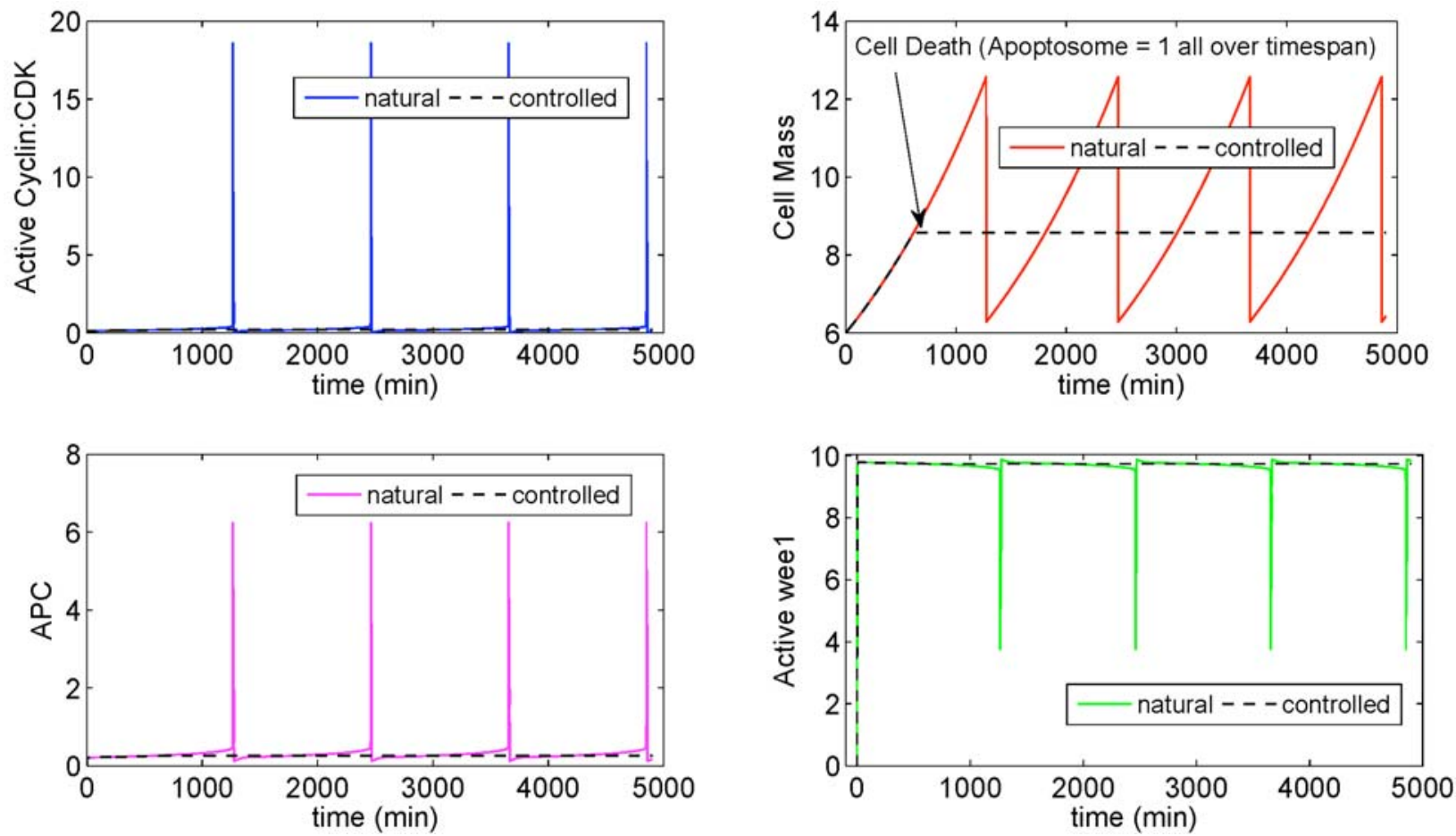

Fig. (13). $G_{1} / S \div G_{2} / M$ transition species and cell mass evolution (growth not halted and DNA damage starting at $t=0 \mathrm{~min}$ ).

In our model, at $\mathrm{t}=235.7 \mathrm{~min}$, a second instability of active cyclin-CDK and APC is connected with both p21mRNA and apoptotic gene overexpressions. After a natural inertia, $t=236.26 \mathrm{~min}$, this second pathway instability of active cyclin-CDK and APC gives the "green light" to another mitosis. Almost surprisingly, despite this second unexpected division, the cell sizer will not be further affected because daughter cells will grow over a timespan $65.5 \%$ greater than a normal sizer; then, the cell resumes its interpulse frequency (timer) and "mutant" size, the sizer being about one half a normal cell size. If p21mRNA "tracking" signaling is controlled, apoptosis is independent of the two aberrant mitotic processes (one at $\mathrm{t}=75.04 \mathrm{~min}$ and one after $\mathrm{p} 21 \mathrm{mRNA}$ overexpression at $\mathrm{t}=235.7 \mathrm{~min}$ ) and cell death is successfully executed at $t=615.65 \mathrm{~min}$. When the ionizing irradiation signal starts at $\mathrm{t}=1100 \mathrm{~min}$, apoptotic 

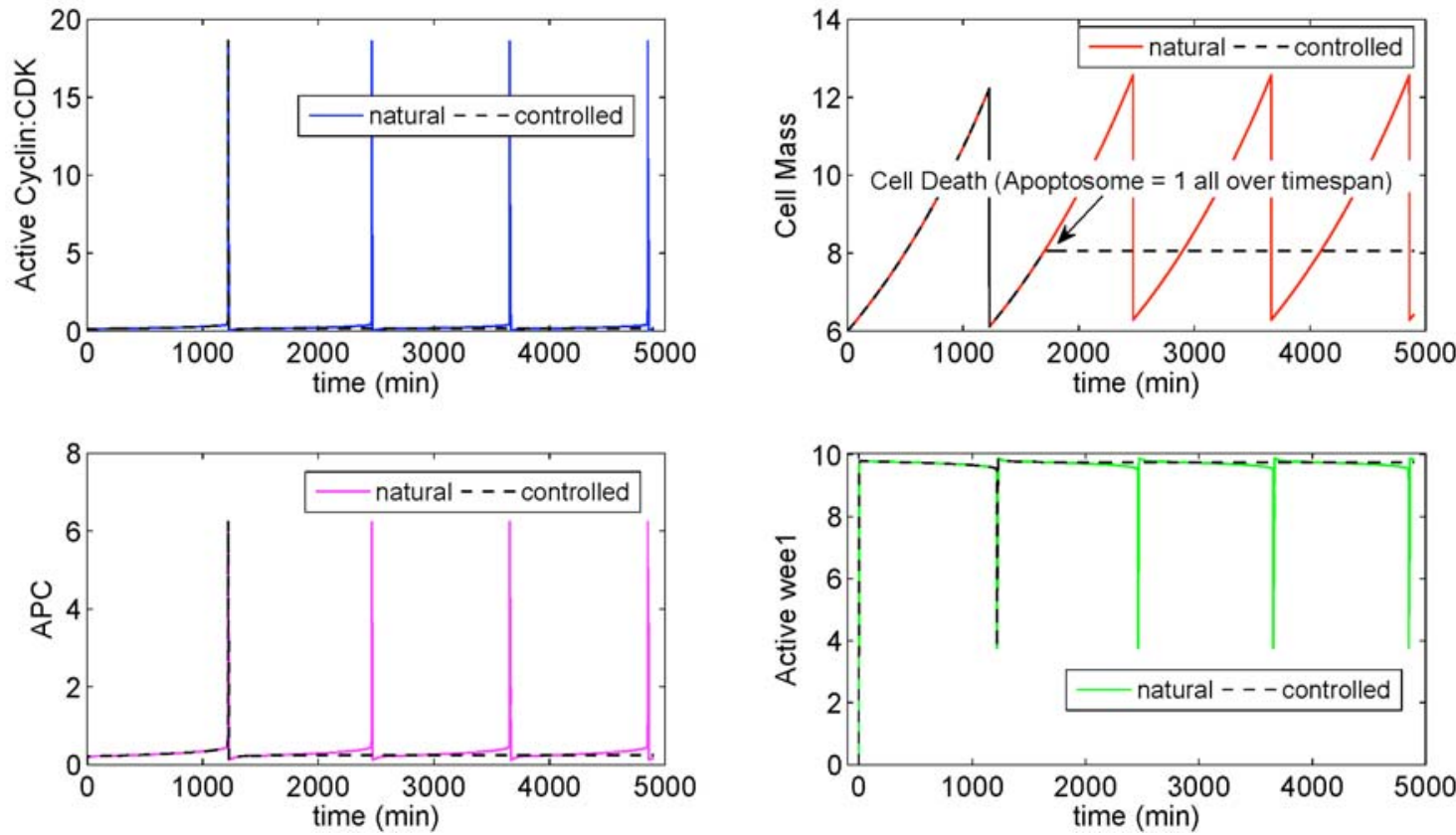

Fig. (14). $G_{1} / S \div G_{2} / M$ transition species and cell mass evolution (growth not halted and DNA damage starting at $t=1100 \mathrm{~min}$ ).
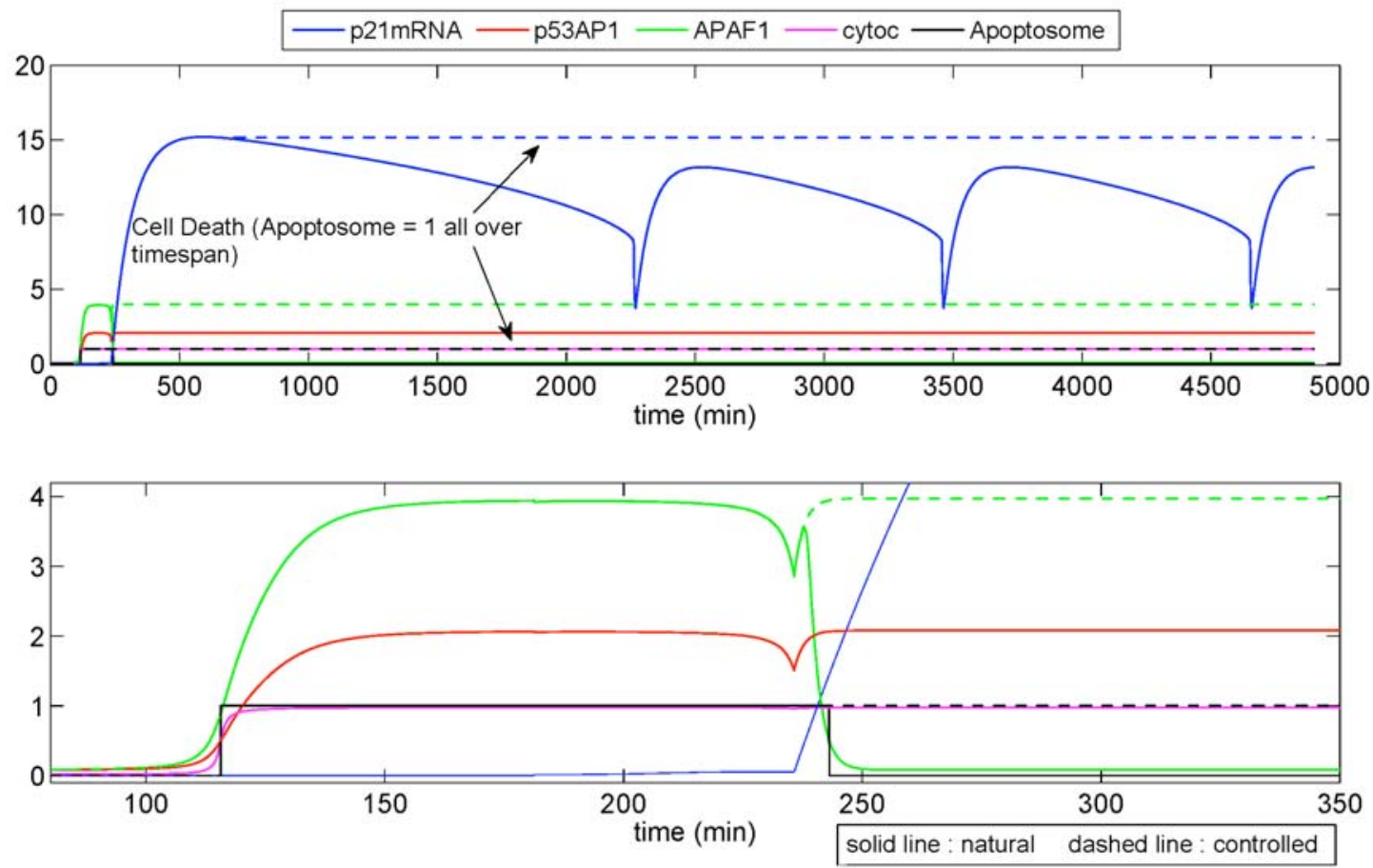

Fig. (15). Output response of apoptotic species network as a consequence of DNA damage at $\mathrm{t}=0 \mathrm{~min}$ for mutant wee1.

network responses are the same (and only shifted) as those obtained for $\mathrm{t}=0 \mathrm{~min}$ (see Fig. (17)). Cell growth factor dynamics, in terms of sizer and timer variations, persist in such a mutant wee1 presence and are qualitatively the same as those displayed in Fig. (16), (see Fig. (18)). Natural p21mRNA "tracking" signal triggering and the extent of the genomic damage (if not completely repaired) push the overall cell system towards tumorigenesis; meanwhile, if p21mRNA upregulation signaling is governed by an optimum control law (dashed line in Fig. (18)) proliferation is halted whatever the cell divisions. Similarly, when the ionizing irradiation signal is emitted at $\mathrm{t}=1100 \mathrm{~min}$ and the third mitotic process is overcome, programmed cell death is executed at $\mathrm{t}=1705.15 \mathrm{~min}$.

\section{DISCUSSION}

To check the reliability of the employed multi-nested digital platform vs. in vitro evidence, we also take into account the analysis of the effects of PML-RAR on p21 in p53 for leukaemia stem cells showed by Viale et al. [55] in which p21 upregulation by PML-RAR is p53-independent. Once the digital platform was tuned to replicate this network 

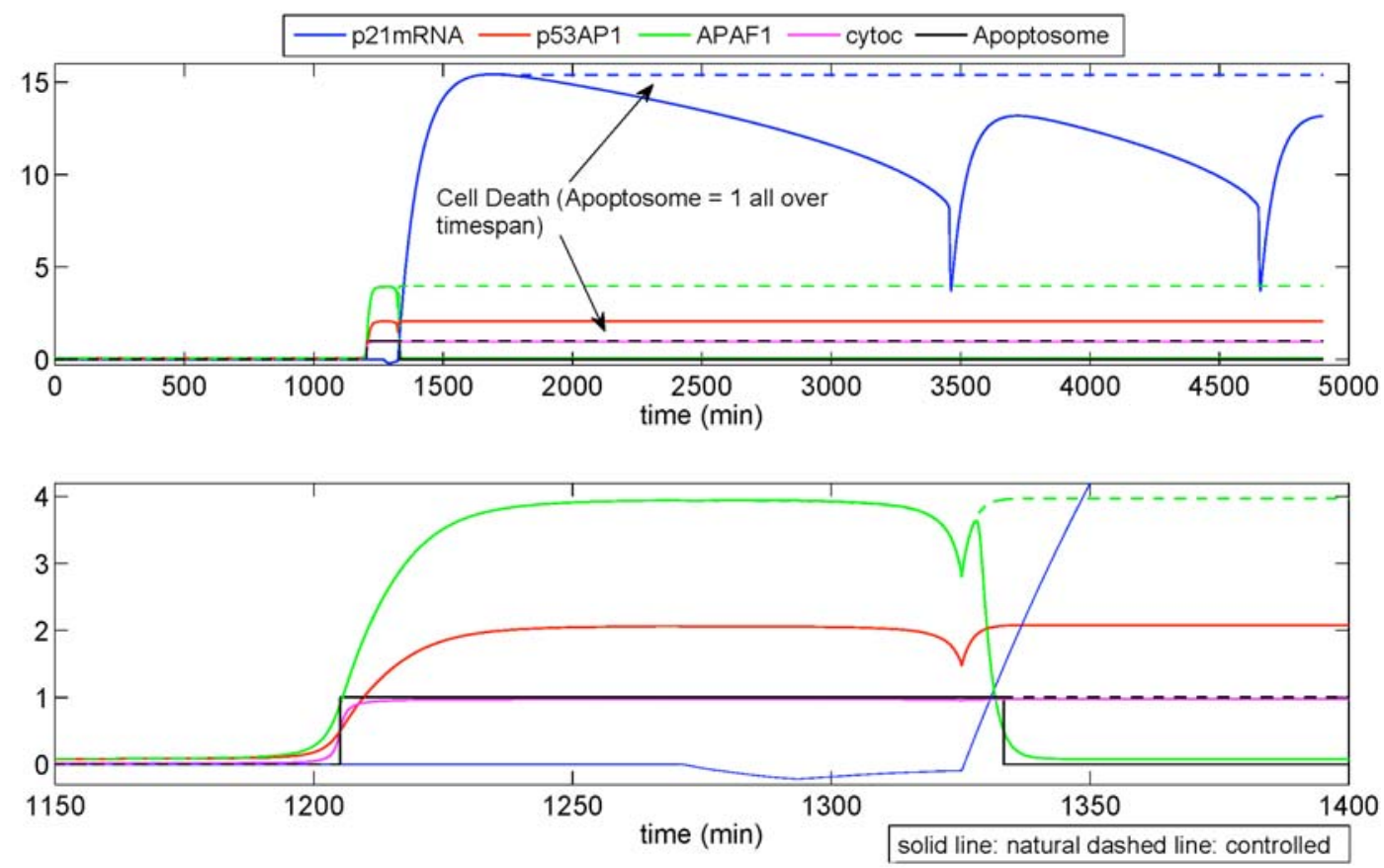

Fig. (16). Output response of apoptotic species network as a consequence of DNA damage at $\mathrm{t}=1100 \mathrm{~min}$ for mutant wee1.
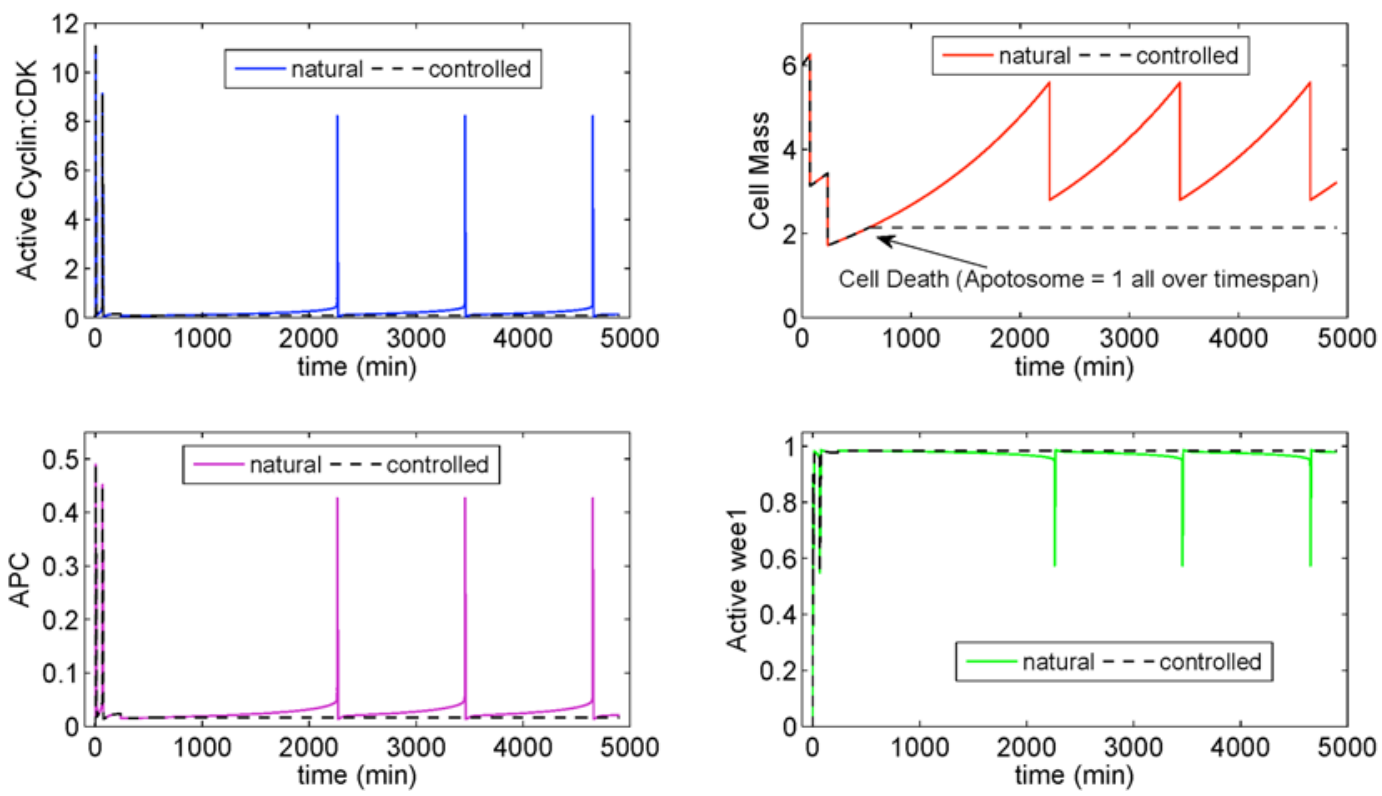

Fig. (17). $G_{1} / S \div G_{2} / M$ transition species and cell mass evolution (growth not halted and DNA damage starting at $t=0$ min) for mutant wee1.

signaling, we obtained a frequency (for two pulses) of 7.4 $10^{-5}$ vs. $7.09210^{-5}$ and a relative error of $4 \%$ (data not shown).

In agreement with but differently from Viale et al., we deduce and confirm that p21mRNA upregulation is p53independent over the initial frame of the global timespan. The discrepancy between our results and those of these authors is superficial not only computationally speaking. In fact, the overexpression of p21mRNA digitally triggers within a very small interval and its intensity (and gradient), more similar to a saturation signal, is quite different from those of the other gene expressions. This behavior, typically digital, implies two effects: first, p21mRNA upregulation becomes almost invisible when one has to evaluate its effects in back-reactions and experimental tools might fail in detecting it unless they are provided with suitable digital plug-ins; secondly, if one admits as negligible the p53dependence of $\mathrm{p} 21 \mathrm{mRNA}$ overexpression, this could become supercritical for the apoptotic network. Roughly speaking, the involvement of p21mRNA in apoptosis avoidance is unveiled taking into account APAF1 as a marker.

In this way, peculiar features of the proposed model are underlined if one considers that these digital cell layers are now capable of detecting and controlling molecule signaling pathways during and (mainly) after the division process if cell growth is not arrested (see Cell Mass panels in Figs. 

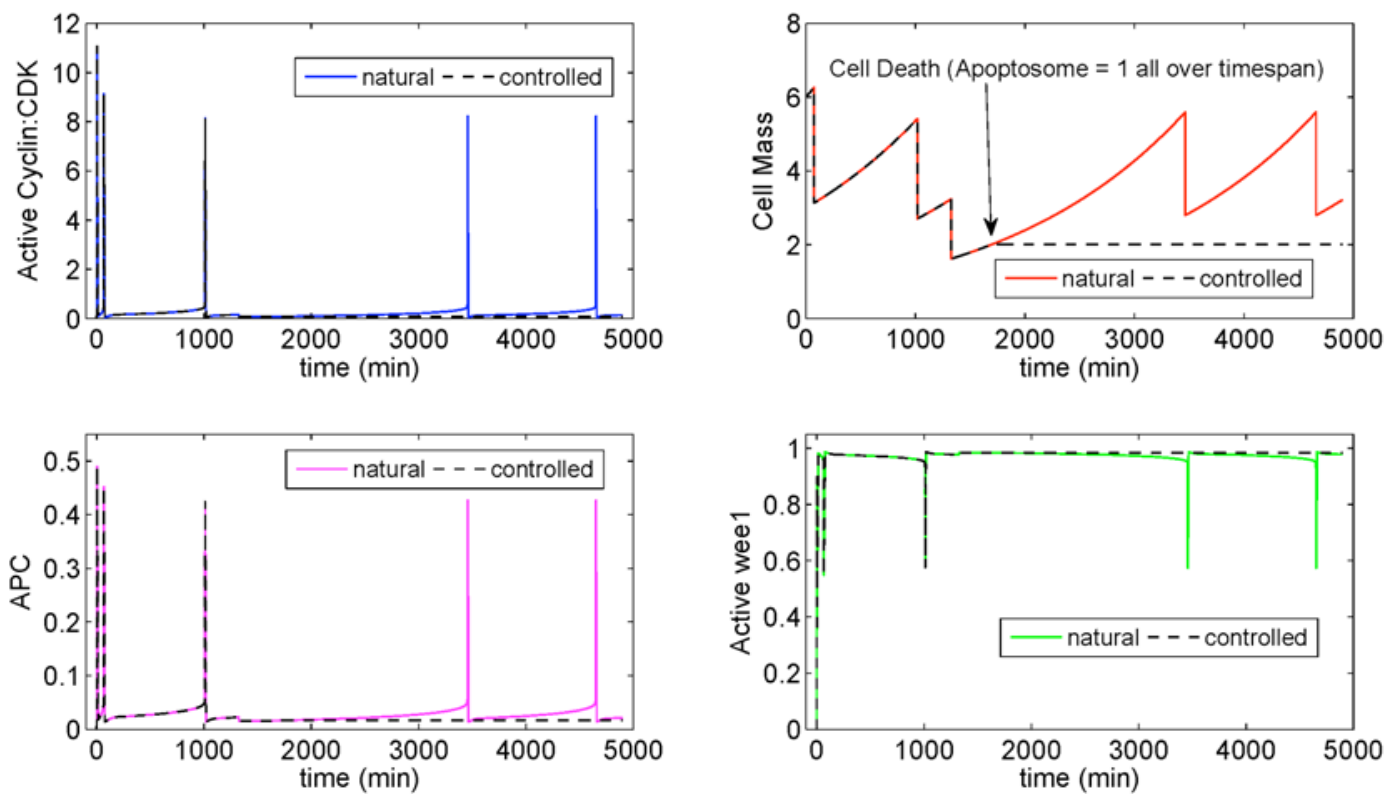

Fig. (18). $G_{1} / S \div G_{2} / M$ transition species and cell mass evolution (growth not halted and DNA damage starting at $t=1100 \mathrm{~min}$ ) for mutant wee1.

$(\mathbf{1 6 , 1 8}))$. In this case, the cell digital control platform is independent of DNA damage triggering and switches itself from single cell to multi-cellular configuration, i.e., it starts to sequence and control cell divisions and acts successively on the cell cycle dynamics parameters of both mother and daughters. In other words, if a damaged genome is detected and $\mathrm{p} 53 / \mathrm{Mdm} 2$ defects, the controlled cell defence resources alarm checkpoints, timers and sizers to avoid proliferation and/or execute programmed cell death. This set of byproducts is digitally highlighted by the peculiar and different double-pulsing outfits of p21mRNA (chorally with activeCDK complex, cell mass, wee1 and APC) depending both on apoptotic gene instabilities and cell cycle time windows. As regards the apoptotic species network only, it switches on the alert at an exact time location, i.e., when the target gene gradients---even though still growing---start to invert their time rates. This universal convergence criterion leads to the gene gradients for decrypting the apoptosis code. The proposed cell digital simulator model demonstrates how the whole cell apoptosis network rigorously falls into line with this principle and suggests the mechanism for apoptosis stimulation and stabilization.

\section{ACKNOWLEDGEMENTS}

The authors are indebted and grateful to Doctor Michael Carley for his assistance in running and supervising all the recursive routines, digital multi-layers and circuitries that were processed using Matlab ${ }^{\mathrm{TM}} /$ Simulink $^{\mathrm{TM}}$ platforms at the Department of Mechanical Engineering, University of Bath (UK). Marzia Sabella and Notre Dame du Cap de La Madeleine made this work possible.

\section{REFERENCES}

[1] Qu, Z.; MacLellan, R.; Weiss, N. Dynamics of the cell cycle: checkpoints, sizers, and timers. Biophys. J., 2003, 85, 3600-11.

[2] Qu, Z.; Weiss, J.N.; MacLellan, W.R. Regulation of the mammalian cell cycle: a model of the G1-to-S transition. Am. J. Physiol. Cell Physiol., 2003, 284, C349-C64.
[3] Masui, Y.; Wang, P. Cell cycle transition in early embryonic development of Xenopus laevis. Biol. Cell., 1998, 90, 537-48.

[4] Montagne, J.; Stewart, M.J.; Stocker, H.; Hafen, S.C.; Kozma, S.C.; Thomas, G. Drosophila S6 kinase: a regulator of cell size. Science, 1999, 285, 2126-29.

[5] Meek, D.W. The p53 response to DNA damage. DNA Repair (Amst.), 2004, 3, 1049-56.

[6] Aguda, B.D. A quantitative analysis of the kinetics of the G(2)DNA damage checkpointsystem. Proc. Natl. Acad. Sci. U.S.A., 1999, 96, 11352-57.

[7] Aguda, B.D.; Tang, Y. The kinetic origins of the restriction point in the mammalian cell cycle. Cell Prolif., 1999, 32, 321-35.

[8] Chen, K.C.; Csikaz-Nagy, A.; Gyorffy, B.; Val, J.; Novak, B.; Tyson J.J. Kinetic analysis of a molecular model of the budding yeast cell cycle. Mol. Biol. Cell, 2000, 11, 369-91.

[9] Gardner, T.S.; Dolnik, M.; Collins, J.J. A theory for controlling cell cycle dynamics using a reversibly binding inhibitor. Proc. Natl. Acad. Sci. U.S.A., 1998, 95, 14190-95.

[10] Goldbeter, A. A minimal cascade model for the mitotic oscillator involving cyclin and cdc2 kinase. Proc. Natl. Acad. Sci. U.S.A., 1991, $88,9107-11$

[11] Hatzimanikatis, V.; Lee, K.H.; Bailey, J.E. A Mathematical description of regulation of the G1-S transition of the mammalian cell cycle. Biotechnol. Bioeng., 1999, 65, 631-37.

[12] Novak, B.; Tyson, J.J. Modeling the control of DNA replication in fission yeast. Proc. Natl. Acad. Sci. U.S.A., 1997, 94, 9147-52.

[13] Obeyesekere M.N.; Knudsen, E.S.; Wang J.Y.J.; Zimmerman, S.O. A mathematical model of the regulation of the $\mathrm{G}(1)$ phase of $\mathrm{Rb}^{+/+}$ and $\mathrm{Rb}^{-1-}$ mouse embryonic fibroblast and an osteosarcoma cell line. Cell Prolif., 1997, 30, 171-94.

[14] Thron, C.D. Cell Cycle Controls, Computational Cell Biology; Springer: New York, Berlin, 1997.

[15] Tyson, J.J.; Chen, K.; Novak, B. Network dynamics and cell physiology. Nat. Rev. Mol. Cell. Biol., 2001, 2, 908-16.

[16] Tyson, J.J.; Csicasz-Nagy, A.; Novak, B. The dynamics of cell cycle regulation. Bioessays, 2002, 24, 1095-09.

[17] Tyson, J.J.; Novak, B. Regulation of the eukaryotic cell cycle: molecular antagonism, hysteresis, and irreversible transition. $J$. Theor. Biol., 2001, 210, 249-63.

[18] Zhang, Y.; Henson, M. Bifurcation analysis of countinuous biochemical reactors. Biotechnology, 2001, 17, 647-60.

[19] Zhang, T.; Brazhnik, P.; Tyson, J.J. Exploring mechanisms of the DNA-damage response. Cell Cycle, 2007, 1, 85-94.

[20] Zhang, T.; Brazhnik, P.; Tyson, J.J. Computational analysis of dynamical responses to the intrinsic pathway of programmed cell death. Biophys. J., 2009, 97, 415-34. 
[21] Borisuk, M.T.; Tyson, J.J. Bifurcation analysis of a model of mitotic control in frog eggs. J. Theor. Biol., 1998, 195, 69-85.

[22] Wang, Y.; Penfold, S.; Tang, X.; Hattori, N.; Riley, P.; Harper, J.W.; Cross, J.C.; Tyres, M. Deletion of the Cull1 gene in mice causes arrest in early embryogenesis and accumulation of cyclin E. Curr. Biol., 1999, 9, 1191-94.

[23] Bar Or, R.L.; Maya, R.; Segel, L.A.; Alon, U.; Levine, A.J.; Oren, M. Generation of oscillations by the p53-Mdm2 feedback loop: a theorethical and experimental study. Proc. Natl. Acad. Sci. U.S.A., 2000, 21, 11250-55.

[24] Batchelor, E.; Mock, C.S.; Bhan, I.; Loewer, A.; Lahav, G. Recurrent initiation: a mechanism for triggering p53 pulses in response to DNA damage. Mol. Cell., 2008, 30, 277-89.

[25] Bates, S.; Phillips, A.C.; Clark, P.A.; Stott, F.; Peters, G.; Ludwig, R.L.; Vousden, K.H. p14 ${ }^{A R F}$ links the tumour suppressor RB and p53. Nature, 1998, 395, 124-25.

[26] Sveiczer, A.; Novak, B.; Mitchison, J.M. The size control of fission yeast revisited. J. Cell Sci., 1999, 112, 1085-92.

[27] Ardito Marretta, R.M.; Barbaraci, G. Digital control circuitry of cancer cell and its apoptosis. Mol. Cell. Biomech., 2009, 6, 175-89.

[28] Bell, S.; Klein, C.; Muller, L.; Hansen, S.; Buchner, J. p53 contains large unstructured regions in its native state. J. Mol. Biol., 2002, $322,917-27$

[29] Bose, I.; Ghosh, B. The p53-MDM2 network: from oscillations to apoptosis. J. Biosci., 2007, 32, 991-97.

[30] Ciliberto, A.; Novak, B.; Tyson, J.J. Steady states and oscillations in the p53/Mdm2 network. Cell Cycle, 2005, 4, 488-93.

[31] Dealy, M.J.; Nguyen, K.V.; Lo, J.; Gstaiger, M.; Krek, W.; Elson, D.; Arbeit, J.; Kipreos, E.T.; Johnson, R.S. Loss of Cull1 results in early embryonic lethality and dysregulation of cyclin E. Nat. Genet., 1999, 23, 245-48.

[32] Fiscella, M.; Zhang, H.; Fan, S.; Sakaguchi, K.; Shen, S.; Mercer, W.E.; Vande Woude, G.F.; O'Connor, P.M.; Appella, E. Wip 1, a novel human protein phosphatase that is induced in response to ionizing radiation in a p53-dependent manner. Proc. Natl. Acad. Sci. U.S.A., 1997, 94, 6043-53.

[33] Fodde, R.; Smits, R. A matter of dosage. Science, 2002, 298, 76163.

[34] Fotedar, R.; Bendjennat, M.; Fotedar, A. Functional analysis of CDK inhibitor $\mathrm{p} 21^{(\mathrm{WAF1})}$. Methods Mol. Biol., 2004, 281, 55-71.

[35] Geva-Zatorsky, N.; Rosenfeld, N.; Itzkovitz, S.; Milo, R.; Sigal, A.; Dekel, E.; Yarnitzky, T.; Liron, Y.; Polak, P.; Lahav, G.; Alon, U. Oscillations and variability in the p53 system. Mol. Syst. Biol., 2006, 2, 2006.0033.

[36] Ghosh, B.; Bose, I. Gene copy number and cell cycle arrest. Phys. Biol., 2006, 3, 29-36.

[37] Haupr, S.; Berger, M.; Goldberg, Z.; Haupr, Y. Apoptosis - the p53 network. J. Cell Sci., 2003, 116, 4077-85.

[38] Hohenstein, P. Tumour suppressor genes-one hit can be enough. PLoS Biol., 2004, 2, 165-66.

[39] Knudson, A.G. Mutation and cancer: statistical study of retinoblastoma. Proc. Natl. Acad. Sci. U.S.A., 1971, 68, 820-23.

[40] Lahav, G.; Rosenfeld, N.; Sigal, A.; Geva Zatorsky, N.; Levine, A.J.; Elowitz, M.B.; Alon, U. Dynamics of the p53-Mdm2 feedback loop in individual cells. Nat. Genet., 2004, 36(2), 147-50.
[41] Loewer, A.; Lahav, G. Cellular conference call: external feedback affect cell-fate decision. Cell, 2006, 24, 1128-30.

[42] Ma, L.; Wagner, J.; Rice, J.J.; Hu, W.; Levine, A.J.; Stolovitzky, G.A. A plausible model for the digital response of p53 to DNA damage. Proc. Natl. Acad. Sci. U.S.A., 2005, 40, 14266-71.

[43] Montagnoli, A.; Fiore, F.; Eytan, N.; Carrano, A.C.; Draetta G.F.; Hershko, A.; Pagano, M. Ubiquitination of p27 is regulated by Cdk-dependent phosphorylation and trimeric complex formation. Gen. Dev., 1999, 13, 1181-89.

[44] Morris, M.C.; Heitz, A.; Mery, J.; Heitz, F.; Divita, G. An essential phosphorylation-site domain of human cdc25C interacts with both 14-3-3 anc cyclins. J. Biol. Chem., 2000, 275, 28849-57.

[45] Nakayama, K.I.; Hatakeyama, S.; Nakayama, K. Regulation of the cell cycle at the $\mathrm{G}_{1}-\mathrm{S}$ transition by proteolysis of cyclin $\mathrm{E}$ and p27 $7^{\text {Kip1 }}$. Biochem. Biophys. Res. Commun., 2001, 282, 853-60.

[46] Oda, K.; Atakawa, H.; Tanada, T.; Matsuda, K.; Tanikawa, C. Mori, T.; Nishimori, H.; Tanai, K.; Tokino, T.; Nakamura, Y.; Taya, Y. p53AIP1, a potential mediator of p53-dependent apoptosis, and its regulation by SER-46 phosphorilated p53. Cell, 2000, 102, 849-62.

[47] Vousden, K.H.; Lu, X. Live or let die. The cell's response to p53. Nat. Rev. Cancer, 2002, 2, 594-04.

[48] Reich, C.N.; Oren, M.; Levine, A.J. Two distinct mechanisms regulate the levels of a cellular tumor antigen, p53. Mol. Cell. Biol., 1983, $12,2143-50$

[49] Shangary, S.; Wang, S. Targeting the Mdm2-p53 interaction for cancer therapy. Clin. Cancer Res., 2008, 17, 5318-24.

[50] Song, W.J. Haploinsufficiency CBFA2 causes familial thrombocytopenia with propensity to develop acute myelogenous leukaemia. Nat. Genet., 1999, 23, 166-75.

[51] Sveiczer, A.B.; Novak, B.; Mitchison, J.M. The size control of fission yeast revisited. J. Cell Sci., 1999, 109, 2947-57.

[52] Vassilev, L.T.; Vu, B.T.; Graves. B.; Carvajal, D.; Podlaski, F.; Filipovic, Z.; Kong, N.; Kammlott, U.; Lukacs, C.; Klein, C.; Fotouhi, N.; Liu, E.A. In vivo activation of the p53 pathway by small-molecule antagonist of Mdm2. Science, 2004, 303, 1889-93.

[53] Venkatachalan, S.; Shi, Y.P.; Jones, S.N.; Vogel, H.; Bradley, A.; Pinkel, D. Retention of wild-type p53 in tumours from p53 heterozygous mice: reduction of p53 dosage can promote cancer formation. EMBO J., 1998, 17, 4657-67.

[54] Ventura, A.; Kirsch, D.G.; McLaughlin, M.E.; Tuveson, D.A.; Grimm, J.; Lintault, L.; Newman, J.; Reczek, E.E.; Weissleder, R.; Jacks, T. Restoration of $\mathrm{p} 53$ function leads to tumour regression in vivo. Nature, 2007, 445, 661-65.

[55] Viale, A.; De Franco, F.; Orleth, A.; Cambiaghi, V.; Giuliani, V.; Bossi, D.; Ronchini, C.; Ronzoni, S.; Muratore, I.; Monestiroli, S.; Gobbi, A.; Alcalay, M.; Minacci, S.; Pelicci, P.G. Cell-cycle restriction limits DNA damage and maintains self-renewal of leukaemia stem cells. Nature, 2009, 457, 51-7.

[56] Vlach, J.; Henneke, S.; Amati, B. Phosphorylation-dependent degradation of the cyclin-dependent kinase inhibitor p27. EMBO J., 1997, 19, 5334-44.

(C) Marretta and Ales; Licensee Bentham Open

This is an open access article licensed under the terms of the Creative Commons Attribution Non-Commercial License (http://creativecommons.org/licenses/by-nc/3.0/) which permits unrestricted, non-commercial use, distribution and reproduction in any medium, provided the work is properly cited. 